\title{
Multi-year optimization of malaria intervention: a mathematical model
}

\author{
Harry J. Dudley ${ }^{1}$, Abhishek Goenka², Cesar J. Orellana ${ }^{2}$ and Susan E. Martonosi ${ }^{2^{*}}$
}

\begin{abstract}
Background: Malaria is a mosquito-borne, lethal disease that affects millions and kills hundreds of thousands of people each year, mostly children. There is an increasing need for models of malaria control. In this paper, a model is developed for allocating malaria interventions across geographic regions and time, subject to budget constraints, with the aim of minimizing the number of person-days of malaria infection.

Methods: The model considers a range of several conditions: climatic characteristics, treatment efficacy, distribution costs, and treatment coverage. An expanded susceptible-infected-recovered compartment model for the disease dynamics is coupled with an integer linear programming model for selecting the disease interventions. The model produces an intervention plan for all regions, identifying which combination of interventions, with which level of coverage, to use in each region and year in a 5 -year planning horizon.
\end{abstract}

Results: Simulations using the model yield high-level, qualitative insights on optimal intervention policies: The optimal intervention policy is different when considering a 5-year time horizon than when considering only a single year, due to the effects that interventions have on the disease transmission dynamics. The vaccine intervention is rarely selected, except if its assumed cost is significantly lower than that predicted in the literature. Increasing the available budget causes the number of person-days of malaria infection to decrease linearly up to a point, after which the benefit of increased budget starts to taper. The optimal policy is highly dependent on assumptions about mosquito density, selecting different interventions for wet climates with high density than for dry climates with low density, and the interventions are found to be less effective at controlling malaria in the wet climates when attainable intervention coverage is $60 \%$ or lower. However, when intervention coverage of $80 \%$ is attainable, then malaria prevalence drops quickly in all geographic regions, even when factoring in the greater expense of the higher coverage against a constant budget.

Conclusions: The model provides a qualitative decision-making tool to weigh alternatives and guide malaria eradication efforts. A one-size-fits-all campaign is found not to be cost-effective; it is better to consider geographic variations and changes in malaria transmission over time when determining intervention strategies.

Keywords: Malaria policy, Operations research, Compartment model, Integer programming

\section{Background}

Malaria remains a lethal disease affecting an estimated 200 million people and killing 627,000 in 2012 [1]. There are a variety of interventions for treating or preventing malaria infection, but the use of these interventions is hindered by scarcity of resources. Mathematical models

*Correspondence: martonosi@g.hmc.edu

${ }^{2}$ Harvey Mudd College, 301 Platt Blvd, Claremont, CA 91711, USA

Full list of author information is available at the end of the article provide a useful tool for evaluating intervention strategies and studying the relative effectiveness of interventions. These evaluations will become increasingly useful as success with malaria elimination is predicted to change transmission dynamics. In fact, the WHO Global Malaria Programme cites the specific need for operations research models to determine the best intervention strategies in areas where transmission dynamics are changing as malaria is being eliminated [2].

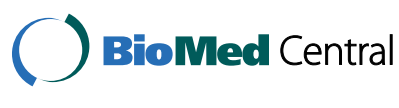


In this paper, an integer linear program (ILP) and a coupled susceptible-infected-recovered (SIR) compartment model are developed to create a decision-making tool for planning future interventions. The model suggests the best strategy for minimizing person-days of malaria infection over a 5 -year period given an initial population, cost of each intervention, and a budget constraint. The model allows for the possibility of a malaria vaccine in combination with other interventions. Simulations are performed in which the budget, the efficacy of the interventions, and their cost are varied to determine the sensitivity of the optimal policy to these parameters.

\section{Interventions}

There are many existing methods to prevent or treat malaria infection. The model will consider the following five interventions and their combinations.

Long-lasting insecticidal nets (LLINs) cover sleeping individuals during the night when mosquito biting can be highest. When intact, the nets block mosquitoes from reaching humans. The insecticides work by deterring mosquitoes from feeding and by killing female mosquitoes that come in contact with the net. LLINs can remain effective for multiple years [3]. In fact, the WHO Pesticide Evaluation Scheme 2005 guidelines state that LLINs should survive at least 3 years of recommended washing and use [4].

Indoor residual spraying (IRS) is another insecticidal prevention method. IRS is believed to deter mosquitoes from entering sprayed areas and to kill female Anopheles mosquitoes that rest on sprayed surfaces after feeding. (Resting after feeding is a hallmark of some mosquito species while others prefer to rest outdoors [5]). Historically, IRS with an insecticide called dichlorodiphenyltrichloroethane was effective in reducing malaria in Europe, Asia, and Latin America. However, as insecticide use increases, insecticide resistance has been observed in some mosquito populations in Africa, and new insecticides must be used [1].

Intermittent preventive therapy (IPT) is the regular administration of a drug like sulfadoxine-pyrimethamnine to decrease morbidity due to malaria in infants, children, and pregnant women. IPT decreases the chance of developing symptoms after being bitten by an infected mosquito [6]. There is evidence that children withstand acute infection better than adults. However, in endemic areas, adults develop acquired immunity from repeated exposures, and children remain more susceptible to high levels of parasitaemia (parasite density in the blood) [7]. Most of the 627,000 people killed by malaria in 2012 were children in Africa, so giving IPT to infants, children, and pregnant women treats the most vulnerable population while limiting the risk of spreading drug resistance [1].
Artemisinin combination therapy (ACT) can be used to treat a patient after they contract malaria. This is the best treatment for uncomplicated $P$. falciparum malaria when confirmed by rapid diagnostic tests (RDT) $[1,8]$. ACT kills the parasites that cause symptoms and may destroy or disable the gametocytes that are responsible for infecting mosquitoes [9]. Both these factors mean that ACT increases the recovery rate.

Many malaria vaccines are in development, and one has gone through Phase III clinical trials. The complex life-cycle of the malaria parasite makes it possible to intervene at many stages. Vaccines that target different forms of the parasite will operate by different mechanisms, but in general, a vaccine would decrease the chance of developing symptoms and increase the recovery rate if infected. The leading malaria vaccine candidate is the RTS,S malaria vaccine. It is an antigen composed of the RTS and S proteins. The RTS,S vaccine is a pre-erythrocytic vaccine that presents circumsporozoite protein (CSP) from malaria sporozoites to the immune system. CSP is a parasitic surface protein that is an important part of the invasion of hepatocytes by sporozoites [10]. Such a vaccine will decrease the probability that a susceptible person becomes infected after a bite from an infectious mosquito. Moreover, it is believed the vaccine could increase a person's recovery rate by increasing their exposure to asexual blood-stage parasites, thereby boosting their immunity [10]. (By contrast, a transmissionblocking vaccine that acts in mosquitoes would decrease the probability of transmission from an infectious mosquito but would not change the human recovery rate).

\section{Literature review}

This paper extends a single-stage optimization model of Dimitrov et al. Their model divides the country of Nigeria into approximately 270,000 cells and chooses one action (either a single intervention or no intervention) for each cell over a year, subject to budget constraints, to minimize societal costs caused by malaria infection. The model also identifies optimal locations for supply distribution centres. They treat the societal benefit of each intervention as an exogenous parameter that depends on geographic characteristics. This allows their model to consider geographic variability in malaria dynamics [11].

However, because malaria dynamics depend on the fraction of the population that is infectious, a quantity that the interventions are themselves trying to reduce, the framework of Dimitrov et al. does not permit the examination of multiyear efforts against malaria in which the optimal policy might vary over time as the malaria dynamics shift. This paper extends the optimization model above to select interventions (or combinations thereof) over multiple years by explicitly incorporating malaria disease dynamics 
over time in response to those interventions. This is a novel approach that combines two areas of mathematics that do not regularly interact: ILP from the area of operations research and differential equations modelling from the area of mathematical epidemiology.

There is a long history of mathematical models of malaria transmission, going back to the work of Sir Ronald Ross in the early 1900s [12, 13]. In recent years, malaria has drawn significant attention from the academic community. Epidemiologists have traditionally modelled the spread of malaria in a population using variations on the SIR model to capture different aspects of the disease. Mandal et al. survey the models found in the literature and offer a hierarchy based on model complexity [13].

In order for the model presented here to make informed choices about which interventions to distribute, the dynamics of how disease transmission change after treatment interventions must first be understood. Lindblade et al. and Killeen et al. study the protective effect of insecticide-treated nets or LLINs [16]. Bousema et al. investigate how ACT reduces the circulation time of gametocytes, thereby reducing infectiousness [16]. Garner and Graves examine the community benefits of ACT [17]. Chandramohan et al., Grobusch et al., and Aponte et al. quantify the protective effects of IPT for infants $[6,18$, 19]. Pluess et al. review the effects of IRS [5]. These results are used to inform the model's choice of disease transmission parameters, as described later under "Effects of interventions on SIR parameters" section.

The model presented here includes in its portfolio of interventions a vaccine that is currently in development. Prosper et al. model the interaction between vaccine- and naturally-acquired immunity using a five-compartment model. Their model augments the $S, I$, and $R$ classes with a partially-immune (due either to vaccination or natural immunity) susceptible class and a moderately-infectious class for infected, partially-immune individuals. They find that disease burden can be decreased only if a highly effective vaccine is coupled with a policy of actively treating asymptomatic infections in partially immune individuals [20]. Bojang et al. report there is minimal potential effect for a malaria vaccine given to adult men, and Asante et al. study the positive potential protective benefits of administering the vaccine to children [21,22].

There are extensions to the SIR framework that are not considered here. Koella and Antia model the reduced efficacy of interventions due to the spread of drugresistant strains of malaria [23]. The model presented here does not incorporate drug-resistance, so any policy recommended by the model should be evaluated in this context. Other researchers, for example Dawes et al. [24] and Koudou et al. [25], focus on the mosquitoes' plasmodial transmission dynamics by analysing the effects of interventions on mosquito morbidity and mortality rates and the usefulness of the resulting manipulation of said rates. The changing mosquito population is not modelled explicitly; instead the effects of interventions on the mosquito population are represented as changes in the parameter values used in the human SIR model.

While the above references provide detailed models of malaria's complex dynamics, this paper presents a simple SIR model that accommodates the effects of several types of interventions, while maintaining the computational tractability required by the optimization model. In the next section, the model and simulation approach are described in greater detail.

\section{Methods}

This paper considers the problem of allocating malaria treatments to many regions when limited by scarce resources. There is assumed to be a fixed annual budget shared across several geographic regions having different initial incidences and transmission rates of malaria and different unit costs for distributing treatment. A portfolio of interventions can be selected, including some in combination, each having its own effects on malaria transmission. Each intervention is selected at a particular coverage, which is the percentage of the population that receives the intervention and uses it correctly. Social and economic losses are assumed to be proportional to the time spent infectious, so person-days of malaria infection is the chosen measure of the malaria burden. The model identifies the optimal sequence of interventions and corresponding coverage percentages for each region and each year that minimizes the total infected person-days over a fixed time horizon.

An integer linear programming optimization model (ILP) suggests the best set of interventions in each year to minimize person-days of malaria infection over all time steps. The ILP takes as input the number of person-days of malaria infection that occur when a given intervention is used on a population with a given initial prevalence of malaria. The person-days of malaria infection is estimated by a SIR differential equations model of malaria transmission dynamics.

\section{Integer linear programming (ILP) model}

The ILP relies on several sets, parameters, and decision variables, which are defined here.

\section{Sets}

Geographic regions Because the cost of distributing an intervention to a particular district depends on its infrastructure and ease of access to treatment, and the malaria transmission dynamics depend on its climate, districts are grouped into geographic regions, denoted by index $g$. 
The optimization model determines the number of districts in each geographic region to receive a particular sequence of interventions.

Population states A population state, $p$, is a triplet, $(S, I, R)$, that indicates the percentage of a district's population susceptible to $(S)$, infected by $(I)$, or recovered from and temporarily immune to $(R)$ malaria. Each district begins a year in a particular population state and ends in a new population state that depends on how the chosen intervention affects the malaria disease dynamics. (The model for determining the disease progression is described in the "Differential equations (DE) model" section).

Actions The set of actions is the set of possible choices of intervention (including certain combinations of interventions, or the possibility of applying no intervention). The choice of intervention at a determined coverage level in a district is referred to as an action, denoted by index $i$.

\section{Parameters}

$A_{i g p q}^{i n} \quad$ is an indicator variable whose value is 1 if action $i$ applied to a district of geographic region $g$, initially in population state $p$ causes a transition to population state $q$, and 0 otherwise.

$A_{i g p}^{\text {out }}$ is an indicator variable whose value is 1 if action $i$ applied to a district of geographic region $g$, initially in population state $p$ causes a transition to a different population state, and 0 otherwise.

$B_{t} \quad$ is the annual budget for year $t$; the combined cost of actions across all districts in year $t$ must not exceed this value.

$C_{i g} \quad$ is the cost of action $i$ in any district in geographic region $g$.

$I_{p g} \quad$ is the number of districts in geographic region $g$ that are initially in population state $p$ at the first time step.

$L_{i p g} \quad$ is the number of person-days of malaria infection incurred in a district in geographic region $g$, initially in population state $p$, under action $i$.

$N \quad$ is a number larger than the total number of population states.

$T$ is the time horizon, in years, considered by the model.

\section{Decision variables}

$P_{p g t} \quad$ is the number of districts in geographic region $g$ that are initially in population state $p$ at the start of year $t$. $a_{\text {ipgt }}^{\text {OUT }}$ is the number of districts in geographic region $g$ that are initially in population state $p$ at the start of year $t$ and are assigned action $i$.

$a_{i p q g t}^{I N} \quad$ is the number of districts in geographic region $g$ that are initially in population state $p$ at the start of year $t$, are assigned action $i$, and end in population state $q$.

\section{Model}

Using these sets, parameters and decision variables, the following ILP can now be defined.

$$
\begin{aligned}
& \min \sum_{t, i, p, g} L_{i p g} a_{i p g t}^{\text {OUT }} \\
& \text { s.t. } \sum_{i, g} C_{i g} \sum_{p} a_{i p g t}^{\text {OUT }} \leq B_{t} \quad \forall t \\
& P_{p, g, t=1}=I_{p g} \quad \forall p, g \\
& \sum_{p} P_{p g t}=\sum_{p} P_{p, g, t+1} \quad \forall g, t \\
& \sum_{i} a_{\text {ipgt }}^{\text {OUT }}=P_{p g t} \quad \forall p, g, t \\
& P_{p g t}+\sum_{i, q} a_{i p q g t}^{I N}-\sum_{i} a_{i p g t}^{\text {OUT }}=P_{p, g, t+1} \quad \forall p, g, t \\
& \sum_{p} a_{i p q g t}^{I N}=a_{i q g t}^{\text {OUT }} \quad \forall i, q, g, t \\
& a_{i p q g t}^{I N} \leq N \cdot A_{i g p q}^{i n} \quad \forall i, p, q, g, t \\
& a_{i p g t}^{\text {OUT }} \leq N \cdot A_{i g p}^{\text {out }} \quad \forall i, p, g, t \\
& P_{p g t}, a_{\text {ipqgt }}^{I N}, a_{\text {ipgt }}^{\text {OUT }} \geq 0 \text {, integer } \quad \forall i, p, q, g, t
\end{aligned}
$$

The objective function in expression (1) minimizes the cumulative person-days that each district spends in the infected state over the time horizon, as a function of the model's choice of actions. Constraint (2) requires the chosen set of interventions to be within budget in each year. Constraint (3) initializes the population variable at the start of the time horizon. Constraints (4), (5), (6) and (7) are bookkeeping constraints that keep track of the number of districts in each geographic region and population state as a function of the actions chosen. Constraints (8) and (9) assure that districts transition out of population state $p$ to population state $q$ only when an appropriate action has been taken. The last 
constraint requires all decision variables to be nonnegative integers.

\section{Differential equations (DE) model}

Several of the parameters used by the ILP model, specifically $A_{i g p q}^{i n} A_{i g p}^{\text {out }}$ and $L_{i p g}$ depend on the dynamics of malaria progression. The SIR model is a standard system of nonlinear ordinary differential equations for analysing the transmission of malaria [13, 23]. In this paper, the standard model is modified to use a coupled six-class compartment model with separate SIR compartments for treated and untreated individuals. This coupling of treated and untreated SIR classes permits modelling of population-wide benefits caused by decreased infectiousness of a treated subpopulation. For an initial population state and action, this system of equations is solved to determine the population state after 1 year. This yields the indicator parameters $A_{i g p q}^{i n}$ and $A_{i g p}^{\text {out }}$. The solution to this system of differential equations is also used to estimate the burden of malaria, measured in infected person-days, during that year. For each district in geographic region $g$, beginning the year in a particular population state $p$, having been assigned action $i$, the infected class curve that results under those conditions is numerically integrated, multiplied by the district's population. This estimates the number of people who are infected over the year times the number of days for which they remain infected. This number is then input into the linear programming model as the value of $L_{i p g}$. This is pre-solved for all possible population states and actions, and the results are stored as input data for the ILP.

The parameters, state variables and system of differential equations are now defined.

\section{Parameters}

$a_{u}\left(a_{t}\right)$ is the number of bites per mosquito per untreated (respectively, treated) human per day.

$b_{u}\left(b_{t}\right) \quad$ is the transmission efficacy from infected mosquito to susceptible, untreated (resp., treated) human.

$c \quad$ is the transmission efficacy from infected human to susceptible mosquito.

$\delta \quad$ is the daily birth rate and death rate. Constant population is assumed.

$\gamma_{u}\left(\gamma_{t}\right)$ is the recovery rate for untreated (resp., treated) people. Its reciprocal is the average time that a person is infected with malaria.

$h_{u}\left(h_{t}\right)$ is the force of infection, that is, the rate at which untreated (resp., treated) susceptible humans become infected with malaria. $m_{u}\left(m_{t}\right)$ is the number of mosquitoes per untreated (resp., treated) human.

$\mu \quad$ is the mosquito mortality rate.

$\omega$ is the duration of immunity without reinfection.

$q \quad$ is the treatment coverage, the percentage of the population that receives a treatment and uses it correctly. It is assumed that the same percentage of newborns are born into the susceptible, treated class. The remaining fraction, $1-q$, are born into the susceptible, untreated class.

$\rho_{u}\left(\rho_{t}\right)$ is rate of immunity loss for recovered untreated (resp., treated) humans.

$\tau$ is the incubation period of malaria in the mosquito.

\section{State variables}

$S_{u}\left(S_{t}\right) \quad$ is the proportion of the population that is susceptible and untreated (resp., treated).

$I_{u}\left(I_{t}\right) \quad$ is the proportion of the population that is symptomatic, infectious, and untreated (resp., treated).

$R_{u}\left(R_{t}\right) \quad$ is the proportion of the population that is recovered with acquired immunity and untreated (resp., treated).

\section{Model}

The proportions of the population belonging to each of the six classes can be determined by solving the following system of differential equations:

$$
\begin{aligned}
& \frac{d S_{u}}{d t}=\delta(1-q)-\left(\delta+h_{u}\right) S_{u}+\rho_{u} R_{u} \\
& \frac{d I_{u}}{d t}=h_{u} S_{u}-\left(\delta+\gamma_{u}\right) I_{u} \\
& \frac{d R_{u}}{d t}=\gamma_{u} I_{u}-\left(\delta+\rho_{u}\right) R_{u} \\
& \frac{d S_{t}}{d t}=\delta q-\left(\delta+h_{t}\right) S_{t}+\rho_{t} R_{t} \\
& \frac{d I_{t}}{d t}=h_{t} S_{t}-\left(\delta+\gamma_{t}\right) I_{t} \\
& \frac{d R_{t}}{d t}=\gamma_{t} I_{t}-\left(\delta+\rho_{t}\right) R_{t} .
\end{aligned}
$$

Although on the surface, the equations for the untreated population and the equations for the treated population 
do not appear to be coupled, the coupling occurs with the parameters $h_{u}$ and $h_{t}$, which are the force of infection parameters. They have been derived by Smith and McKenzie [26] to be:

$$
\begin{aligned}
& h_{u}=\frac{m_{u} a_{u}^{2} b_{u} c e^{-\mu \tau}\left(I_{u}+I_{t}\right)}{\mu+a_{u} c\left(I_{u}+I_{t}\right)} \\
& h_{t}=\frac{m_{t} a_{t}^{2} b_{t} c e^{-\mu \tau}\left(I_{u}+I_{t}\right)}{\mu+a_{t} c\left(I_{u}+I_{t}\right)} .
\end{aligned}
$$

Observe that these rates are functions of the total proportion of infectious people, $I_{u}+I_{t}$, which couples the system of differential equations. The more infectious people there are in either the untreated or treated group, the faster the rate at which susceptible people in either group can become infected.

The rates of immunity loss, $\rho_{u}$ and $\rho_{t}$, are functions of $h_{u}$ and $h_{t}$, respectively and further couple the system. The procedure for deriving the rate of immunity loss has been shown by Aron and May [27]. These equations assume that being exposed to malaria while recovering resets the duration of immunity.

$$
\begin{aligned}
\rho_{u} & =\frac{h_{u}+\delta}{e^{\omega\left(h_{u}+\delta\right)}-1} \\
\rho_{t} & =\frac{h_{t}+\delta}{e^{\omega\left(h_{t}+\delta\right)}-1}
\end{aligned}
$$

This is a general model that does not consider the effect an intervention can have on the transmission of the disease. In the specific case of ACT, a medication that clears infection rapidly, the length of time a malaria patient is carrying infectious gametocytes in her blood is significantly reduced $[16,28]$. Because of this, the model makes the assumption that ACT clears parasites before the body has time to develop acquired immunity; therefore, infected people treated with ACT are assumed to skip the recovered class and transition directly back to the susceptible class. To reflect this, the indicator variable $\psi_{a c t}$ is introduced, which equals 1 when $\mathrm{ACT}$ is chosen (either alone or in combination with another intervention), and 0 otherwise. The state equations for the untreated class are unchanged, and the equations for the treated classes become:

$$
\begin{aligned}
& \frac{d S_{t}}{d t}=\delta q-\left(\delta+h_{t}\right) S_{t}+\rho_{t} R_{t}+\psi_{a c t} \gamma_{t} I_{t} \\
& \frac{d I_{t}}{d t}=h_{t} S_{t}-\left(\delta+\gamma_{t}\right) I_{t} \\
& \frac{d R_{t}}{d t}=\left(1-\psi_{a c t}\right) \gamma_{t} I_{t}-\left(\delta+\rho_{t}\right) R_{t}
\end{aligned}
$$

Observe that when ACT is used, infectious individuals bypass the recovered class and transition directly to the susceptible class.

Because a new portfolio of interventions is selected each year, the effects of treatment are assumed to last for 1 year, exactly. Some of the treatments are known to last longer; for instance, the insecticide coating on mosquito nets is believed to be effective for 3 years, and vaccines in development currently have an efficacy of 3 years. However, assuming a duration of only 1 year is conservative: under this assumption, the model will underestimate the efficacy of the interventions, and the results expected to be seen in the field should be better. Under this assumption, at the end of each year, the six-state population $\left(S_{u}, I_{u}, R_{u}, S_{t}, I_{t}, R_{t}\right)$ can be collapsed into a more compact three-state representation: $\left(S_{u}+S_{t}, I_{u}+I_{t}, R_{u}+R_{t}\right)$.

\section{Coverage}

The coverage, $q$, refers to the percentage of the population that receives a treatment and uses it correctly. For example, if at the start of the year, the percentages of the population who are susceptible, infected and recovered are given by $(S, I, R)$, respectively, then the initial values of $S_{u}, I_{u}, R_{u}, S_{t}, I_{t}$, and $R_{t}$ for the differential equations model will be $(1-q) S,(1-q) I,(1-q) R, q S, q I$, and $q R$, respectively.

However, some interventions, such as IPT and vaccine, are assumed to be distributed only to newborns and children under the age of four. In these cases, the coverage, $q$, applies only to births and to the fraction of the population under the age of four. If $x$ is the fraction of the population under the age of four, and $(S, I, R)$ is the initial distribution of susceptible, infected and recovered individuals in the population, then the initial values of $S_{u}, I_{u}, R_{u}, S_{t}, I_{t}$, and $R_{t}$ for the differential equations model will be $(1-q x) S,(1-q x) I,(1-q x) R, q x S, q x I$, and $q x R$.

\section{Data}

The model relies on parameters governing intervention costs, malaria transmission, and intervention efficacy. When available, parameter values are estimated based on malaria research literature. When using country-specific information, data from Kenya or its neighbours are used as it is more readily available and permits consistency across parameters. This paper also presents sensitivity analysis to understand how the model's results would change under a range of scenarios concerning distribution costs, climate and intervention efficacy. In this section, the costs of the interventions are described first, followed by the baseline parameter values used in the SIR model. Then, the changes in these parameter values 
under interventions and sensitivity analysis scenarios are described.

\section{Base costs of interventions}

The model parameter $C_{i g}$ is the per person, per year cost of action $i$ in any district in geographic region $g$. The cost of an action depends on the purchase price as well as transportation and distribution costs, which are assumed to be regional. For the base cost, the simulations use data provided by White et al., who survey cost and cost-effectiveness data for LLIN, IRS, IPT, and ACT from all available sources and adjust it to 2009 USD [29]. The simulations primarily use data from Kenya, except where noted that no Kenya-specific data was available; in these cases, cost estimates from nearby Ethiopia, Tanzania and Zimbabwe are used.

Listed here are the base costs for each intervention; the subsequent section describes how to modify those costs to reflect transportation and distribution costs in different geographic regions. These are summarized in Table 1.

LLIN The average cost of a single insecticide-treated mosquito net is 7.21 USD [29], and the WHO Pesticide Evaluation Scheme 2005 guidelines estimate a 3 year life span with recommended use [4]. Because the model assumes all actions expire at the end of 1 year, an annual cost per net of 2.40 USD is used, which is one-third the base cost of the net. Moreover, bed-sharing is a common practice that further reduces the per-person cost of each distributed net. The World Health Organization recommends the assumption that an LLIN will protect 1.8 people, on average [30], making the annual per-person cost 1.33 USD.

IRS The IRS cost estimate assumes two rounds of household spraying with lambda cyhalothrin per person per year, at an annual cost of 2.22 USD [29].

IPT White et al. summarize cost estimates for distributing IPT to newborns, children and pregnant women. The mean cost of distributing six bi-monthly doses of sulfadoxine-pyrimethamine to infants in Tanzania is reported to be $0.78 \mathrm{USD}$, and three doses per year to

Table 1 Baseline cost for using interventions, per treated person for 1 year, in 2009 USD [29-31]

\begin{tabular}{ll}
\hline Intervention & Cost \\
\hline None & 0 \\
LLIN & 1.33 \\
ACT & 4.82 \\
IPT & 1.13 \\
IRS & 2.22 \\
Vaccine & 20.66 \\
\hline
\end{tabular}

children in Kenya is 1.25 USD [29]. As roughly $25 \%$ of children under the age of 4 are infants, the simulations use an estimated weighted average annual cost for IPT of 1.13 USD.

$A C T$ White et al. report malaria diagnosis and treatment costs for a variety of diagnostic methods and treatment types in several countries. For consistency, the simulation uses costs associated specifically with RDT used in conjunction with ACT treatment in the countries of Tanzania and Zambia. These range from 3.63 USD to 6.72 USD, with an average of 4.82 USD per person treated [29]. Unlike interventions such as LLINs, which are assumed to be distributed to the entire treated class, ACT is distributed only to members of the treated class who experience a malaria infection. Therefore, the SIR model must estimate the number of new malaria infections per year to determine the annual cost of ACT. According to Eq. (21), new infections occur with rate $h_{t} S_{t}=\frac{d I_{t}}{d t}+\left(\delta+\gamma_{t}\right) I_{t}$. Note that $\frac{d I_{t}}{d t}$ can be approximated by $\frac{I_{t}(d+\epsilon)-I_{t}(d)}{\epsilon}$ for small $\epsilon$. Discretizing the year over which the treatment is available into 365 days and letting $\epsilon=1$ day, the number of new infections appearing on day $d$ should be roughly $I_{t}(d)-\left(1-\left(\delta+\gamma_{t}\right)\right) I_{t}(d-1)$ times the total population. Summing this value over all days $d$ should give an approximation of the number of new infections incurred during the year, and hence, the number of people who received ACT.

Vaccine Cost data for the RTS,S vaccine is not yet available since the vaccine is not yet on the market. Seo et al. use an estimate of 7 USD per dose for the vaccine after looking at recent introductory vaccine prices ranging from 1 to 15 USD [31]. They also propose using 0.37 USD administration cost per vaccination based on the price for other vaccines used in Malawi in the Expanded Program on Immunization (EPI). Because the RTS,S vaccine is administered in three doses, they estimate the total cost of the vaccine at 22.11 USD per person per year [31]. Adjusting their 2012 costs to 2009 values for consistency yields a cost of 20.66 USD per treated person per year [32].

\section{Baseline SIR model parameter values}

The baseline parameter values used in the SIR model are now described; the following section discusses how the interventions and modelling assumptions affect those values. This information is summarized in Table 2 .

- $a_{u}$ is the number of bites per mosquito per untreated human per day, which is estimated to be 0.25 [33].

- $b_{u}$ is the transmission probability from infected mosquito to susceptible, untreated human, which is estimated to be 0.022 [33]. 
Table 2 Malaria transmission parameter values for the baseline, untreated case (corresponding to the subscript " $u$ ") and treatment cases (corresponding to the subscript " $t$ ")

\begin{tabular}{|c|c|c|c|c|c|c|c|}
\hline \multirow[t]{2}{*}{ Symbol } & \multirow[t]{2}{*}{ Description } & \multirow{2}{*}{$\begin{array}{l}\text { Baseline value } \\
\text { (untreated) }\end{array}$} & \multicolumn{5}{|l|}{ Treatment value } \\
\hline & & & LLIN & IRS & IPT & ACT & Vaccine \\
\hline$a_{u} a_{t}$ & Bites per mosquito per human per day & $0.25[33]$ & $a_{u}(1-\beta)[15]$ & & & & \\
\hline$b_{u}, b_{t}$ & $\begin{array}{l}\text { Transmission efficacy from infected mosquito to } \\
\text { susceptible, untreated human }\end{array}$ & $0.022[33]$ & & & 0.0047 & & 0.005 \\
\hline$\beta$ & Proportion of bites that would occur while sleeping & & $0.8[15]$ & & & & \\
\hline c & $\begin{array}{l}\text { Transmission efficacy from infected human to } \\
\text { mosquito }\end{array}$ & $0.36[33]$ & & & & & \\
\hline$\delta$ & $\begin{array}{l}\text { Daily birth rate and death rate assuming constant } \\
\text { population }\end{array}$ & $4.7895 * 10^{-5}[34]$ & & & & & \\
\hline$\gamma_{u} \gamma_{t}$ & Recovery rate in humans & $\frac{1}{180}[35]$ & & & & $\frac{1}{10}$ & $\frac{1}{5.5}$ \\
\hline$m_{u}, m_{t}$ & Mosquitoes per human & $20[13]$ & $m_{u}(1-\beta \chi L L I N)$ & $\begin{array}{l}m_{u, I R S}=m_{u}\left(1-q \chi_{I R S_{u}}\right) \\
m_{t}=m_{u}\left(1-\chi_{\mid R S_{t}}\right)[38]\end{array}$ & & & \\
\hline$\mu$ & Mosquito mortality rate & $0.095[35,36]$ & & & & & \\
\hline$\omega$ & Duration of immunity without reinfection & 274 days [37] & & & & & \\
\hline 9 & Treatment coverage & $0.2,0.4$ or 0.6 & & & & & \\
\hline$\tau$ & Incubation period in mosquito & 10 days [36] & & & & & \\
\hline$x$ & Fraction of the population & $0.146[34]$ & & & & & \\
\hline & $0-4$ years of age & & & & & & \\
\hline XLLIN & $\begin{array}{l}\text { Probability of mosquito mortality when exposed to } \\
\text { a treated net }\end{array}$ & & $0.8[14]$ & & & & \\
\hline$\chi_{R R S t}$ & $\begin{array}{l}\text { Percent reduction in mosquito density in a house } \\
\text { treated with IRS }\end{array}$ & & & $0.95[38]$ & & & \\
\hline$\chi_{I R S_{u}}$ & $\begin{array}{l}\text { Percent reduction in mosquito density in an } \\
\text { untreated house when all nearby houses are } \\
\text { treated with IRS }\end{array}$ & & & $0.5[38]$ & & & \\
\hline
\end{tabular}

In the baseline value column, an empty space means that the parameter does not apply to the baseline, untreated case. In the treatment value columns, an empty space means that the parameter is unchanged by that particular intervention

- $c$ is the transmission probability from infected human to susceptible mosquito, which is estimated to be $0.36[33]$.

- $\delta$ is the daily birth rate and death rate. In Kenya in 2014, the estimated annual birth rate was 0.02827 births per person, and the estimated annual death rate was 0.007 deaths per person [34]. Because the model assumes a constant population, the average of these, or 0.017635 births (deaths) per person per year, is converted using compounding to a daily birth (death) rate of $\delta=4.7895 \times 10^{-5}$.

- $\gamma_{u}$ is the recovery rate for untreated people. Filipe et al. estimate the average infectious period for untreated people to be 180 days, making $\gamma_{u}=\frac{1}{180}$ [35].

- $m_{u}$ is the mosquito density (number of mosquitoes per untreated human), which is estimated to be 20 [13].

- $\mu$ is the mosquito mortality rate, estimated to be 0.095 days $^{-1}[35,36]$.
- $\omega$ is the duration of immunity without reinfection. The value $\omega=274$ days, is based on an estimate that immunity lasts between 6 and 12 months [37].

- $q$ is the treatment coverage, the percentage of the population that receives a treatment and uses it correctly. Three levels of treatment coverage for each intervention are considered: high $(60 \%)$, medium (40\%), and low (20\%).

- $\tau$ is the incubation period in the mosquito, estimated to be 10 days [36].

- $x$ is the fraction of the population that is age 4 years or younger, which was approximately $14.6 \%$ in Kenya in 2014 [34].

The expressions given in Eqs. (16), (17), (18) and (19) are used to determine the force of infection $\left(h_{u}\right.$ and $\left.h_{t}\right)$ and the recovery rate $\left(\rho_{u}\right.$ and $\left.\rho_{t}\right)$.

Note that the malaria transmission parameters, $a_{u}, b_{u}$, $c$, and $m_{u}$, are very location-specific (see [36], p. 409). 
Adapting this model to any location would require reestimating these parameters.

\section{Effects of interventions on SIR parameters}

Each intervention, or combination of interventions, is modelled as affecting a subset of the above parameters.

LLINs protect individual users by decreasing the biting rate, $a_{t}$, and by killing mosquitoes that contact the insecticidal nets, thus decreasing $m_{t}$. The values of $a_{t}$ and $m_{t}$ are estimated as follows:

- Let $\beta$ be the proportion of mosquito exposure that occurs during sleeping hours.

- Let $\chi_{L L I N}$ be the probability of mortality for a mosquito exposed to a treated net.

- As before, let $m_{u}$ be the baseline mosquito density absent any treatment.

Then Killeen et al. [15] derive the value of $a_{t}$ for people using LLIN as

$$
a_{t}=a_{u}(1-\beta),
$$

and the value of $m_{t}$ for people using LLIN as

$$
m_{t}=m_{u}\left(1-\beta \chi_{L L I N}\right) .
$$

Although Fig. 5 in reference [15] shows a slight increase in overall protection for the treated class as a function of $q$, this increase is modest in the range of $q$ considered here, and so $m_{t}$ is assumed to be independent of $q$. Additionally, Killeen et al. suggest that as treatment coverage increases in a population, even non-users of LLINs benefit from decreased mosquito density. However, the authors were unable to find empirical data to support a robust model of mosquito density in the untreated population as a function of treatment coverage; therefore, the model assumes that the untreated population experiences the baseline mosquito density, $m_{w}$, for all values of $q$.

To determine the new biting rate, $a_{t}$, and the new mosquito density, $m_{t}$, for the treated classes, Eqs. (23) and (24), respectively, are used with $\beta=0.8$ [15] and $\chi_{L L I N}=0.8$ [14], and with $a_{u}=0.25$, and $m_{u}=20$ as given earlier.

IRS decreases the number of mosquitoes per treated human, $m_{t}$, in a similar manner as LLINs. Moreover, IRS can also decrease the mosquito density in untreated areas close to treated areas; thus, $m_{u}$ is also affected by IRS [38]. Let $\chi_{I R S_{t}}$ be the reduction in mosquito density in a house treated with IRS, and let $\chi_{I R S_{u}}$ be the reduction in mosquito density in an untreated house when the treatment coverage is $100 \%$ in a nearby area. Then the value of $m_{t}$ for a house treated with IRS is

$$
m_{t}=m_{u}\left(1-\chi_{I R S_{t}}\right)
$$

The value of $m_{u}$ when IRS is used at coverage $q$ is estimated (based on the empirical results of Zhou et al. [38]) to be

$$
m_{u_{I R S}}=m_{u}\left(1-q \chi_{I R S_{u}}\right) .
$$

As [38] report that the mosquito density in treated areas decreases by $95 \%$, and the mosquito density in untreated areas decreases by $50 \%$ when the coverage in nearby treated areas is $100 \%$, the simulations use $\chi_{\text {IRS }}=0.95$ and $\chi_{I R S_{u}}=0.5, m_{u}=20$ as given earlier, and $q$ equal to the coverage associated with the selected action.

IPT decreases the probability, $b_{t}$, that a susceptible person becomes infected after a bite from an infectious mosquito. The authors were unable to find an estimate in the literature for the amount by which the transmission efficacy, $b_{t}$, decreases when a person is using IPT. However, data from several studies reported by Aponte et al. indicate that the protective efficacy against malaria in infants of 1 year of IPT is roughly $30 \%$ [6]. As this should roughly correspond to the percentage decrease in new malaria infections observed in the SIR model output, the model was calibrated by solving the system of differential equations for a range of values for $b_{t}$ and selecting the value of $b_{t}$ that achieves a $30 \%$ reduction in new malaria infections. The value $b_{t}=0.0047$ achieves this percentage reduction.

ACT dramatically reduces the length of time a malaria patient is carrying infectious gametocytes in her blood, possibly down to a mean infectious period of 10 days, so the simulations use $\gamma_{t}=\frac{1}{10}$ days $^{-1}[16,17,28]$.

Vaccine, like IPT, decreases the probability, $b_{t}$, that a susceptible person becomes infected after a bite from an infectious mosquito. Additionally, a vaccine could increase the recovery rate, $\gamma_{t}$, by exposing the immune system to parasite proteins or decreasing the amount of parasites that reach the blood stage initially [10]. Olotu et al. report clinical trial results suggesting that the 4-year reduction in malaria episodes among vaccinated children is $23.5-24.3 \%$ [39]. As this should roughly correspond to the percentage decrease in new malaria infections observed in the SIR model output, the model was calibrated by solving the system of differential equations for a range of values for both $b_{t}$ and $\gamma_{t}$ and selecting the combination that achieves a roughly $24 \%$ reduction in new malaria infections. Choosing $b_{t}=0.005$ and $\gamma_{t}=\frac{1}{5.5}$ days $^{-1}$ achieves this percentage reduction.

Possible actions that can be selected by the optimization model are to deploy no intervention, a single intervention, or a combination of two interventions. Although it is possible to consider combining any pair of interventions, for modelling simplicity, the only pairs 
of interventions considered are those whose coverage applies to the same segments of the population. Therefore, because IPT and vaccines are assumed in the model to be distributed only to newborns and children under the age of four, while LLIN, ACT and IRS are applied to the general population, the combinations considered are IPT with vaccine, LLIN with ACT, LLIN with IRS, or ACT with IRS.

When two interventions are used in combination, it is assumed that the covered segment of the population receives both treatments, and the uncovered segment receives neither. If the two interventions affect non-overlapping parameter sets, it is assumed the combination intervention will affect the union of both sets of parameters in the same manner as the individual interventions. However, some pairs of interventions act upon the same parameter. For example, in the case of LLIN combined with IRS, the mosquito density, $m_{t}$ is affected by both interventions. Because it would be too optimistic to assume that the effects of LLIN and IRS are additive, the model makes a more conservative assumption: the smallest values of $a_{t}, m_{u}$ and $m_{t}$ offered by either LLIN or IRS are used. For the IPT with vaccine combination, $b_{t}$, the transmission efficacy from infected mosquito to susceptible, treated human, is reduced by both interventions via different mechanisms, and $\gamma_{t}$ is increased by the vaccine. Therefore, the smaller of the two $b_{t}$ values under IPT and vaccine (that given by IPT, of $b_{t}=0.0047$ ) and the value of $\gamma_{t}=\frac{1}{5.5}$ yielded by the vaccine are used.

\section{Sensitivity analysis simulations}

The optimal sequence of 5-year interventions in a fictitious nation were simulated and analysed. This nation consists of 4500 districts, each having a population of 10,000 (for a total population of 45 million, comparable to that of Kenya in 2014 [34]). An annual budget of $B_{t}=33.75$ million USD is used, which corresponds to 0.75 USD per person, per year. (This is comparable to the budget for the President's Malaria Initiative (PMI) in Kenya, which in 2013 was 34,256,770 USD [40]).

Each of the 4500 districts is characterized as belonging to one of nine geographic regions, which in turn are characterized by one of three distribution regions and one of three climate regions. 500 districts belong to each of the nine possible combinations. Distribution regions categorize districts by how inexpensively (relative to the baseline costs given earlier) interventions can be distributed to the district. Rural and remote areas are likely to experience higher-than-baseline distribution costs due to having worse road infrastructure and lower access to health centres. Centrally located urban areas are likely to experience lower-than-baseline distribution costs. Districts categorized as having low distribution costs are assumed to have intervention costs that are $20 \%$ lower than the baseline values given in Table 1. Districts categorized as having medium distribution costs will incur the baseline intervention costs, and districts categorized as having high distribution costs will incur intervention costs that are $20 \%$ more than the baseline costs given in Table 1 .

The three climate regions, dry, moderate and wet, reflect the effect climatic characteristics such as temperature and precipitation can have on mosquito population, and hence on malaria transmission dynamics. The moderate climate scenario assumes the baseline mosquito density given above of $m_{u}=20$ mosquitoes per human The dry scenario assumes a mosquito density of $m_{u}=5$ mosquitoes per human, and the wet scenario assumes a mosquito density of $m_{u}=35$ mosquitoes per human. Each region is also characterized by its own initial population distribution amongst the $S, I$ and $R$ classes, which is chosen to be the steady-state population distribution observed when the SIR model is run for a long period of time from a variety of starting population distributions and assuming no intervention. For the moderate climate scenario, the steady-state distribution used for the initial distribution is $15 \%$ susceptible, $15 \%$ infected, and $70 \%$ recovered. The dry scenario uses an initial steadystate distribution of $60 \%$ susceptible, $15 \%$ infected, and $25 \%$ recovered. The wet scenario uses an initial steadystate population distribution of $10 \%$ susceptible, $15 \%$ infected, and $75 \%$ recovered. (For computational tractability, a population state resolution of five percentiles is used, and the SIR population state is rounded to the nearest $5 \%$, while requiring that the percentages over all compartments sum to one).

Three efficacy scenarios are also considered to test the sensitivity of the model to the inherent uncertainty in the efficacy of the interventions. The baseline efficacy scenario uses the baseline parameter estimates described earlier and shown in Table 2. The pessimistic efficacy scenario assumes each parameter value for the treated class is $30 \%$ "worse" than its baseline value, where "worse" means leading to greater malaria infections. The optimistic efficacy scenario assumes each parameter value for the treated class is $30 \%$ "better" than its baseline value. In the case where making a treatment parameter $30 \%$ worse than its baseline value ends up making it worse than the untreated baseline value, the value is capped at the untreated baseline; in this way, a situation is avoided in which the treated class might artificially experience more malaria cases than the untreated class.

\section{Results and discussion}

The results of running the model on this data are now presented. Because a simplified SIR model is used to estimate the social costs of malaria as a function of 
interventions distributed, the purpose of this model is not to give exact estimates of reductions in person-days of malaria infection, but relative results that can be used by the optimization model to make choices between the various interventions. The model provides qualitative insights about trends in the optimal interventions as certain parameters vary; these qualitative insights can then be used to offer high-level policy recommendations, as described below.

Table 3 and Fig. 1 provide the sequence of interventions allocated in each of the nine geographic regions (low, medium or high distribution costs, crossed with dry, moderate or wet climate) over a 5-year horizon in the baseline efficacy case. The total person-days of malaria infection is found to be 4.506 billion. In Fig. 1, the first row of figures corresponds to low distribution costs, the second row to medium distribution costs and the third row to high distribution costs. Likewise, each column of figures corresponds to the same climate region (dry in red, moderate in yellow, wet in blue, from left to right). The vertical axis on each graph lists in alphabetical order the interventions selected by the model at least once in at least one geographic region and the associated coverage. The thickness of a path is proportional to the number of districts (out of 500) that were assigned that sequence of interventions. Table 3 gives the number of districts of each type that are assigned a particular sequence of interventions, as well as the resulting $(S, I, R)$ population state after each year.

Note that for dry climate regions, the sequence of interventions is the same regardless of distribution cost, namely, ACT is distributed to $60 \%$ of the population in year 1 , and then no subsequent interventions are distributed in years $2-5$. The reason for this is that distributing $\mathrm{ACT}$ at a coverage of $60 \%$ in year 1 eradicates (at least subject to rounding at a resolution of $5 \%$ ) malaria, driving the infected proportion of the population to zero. Per Eqs. (16) and (17), the force of infection is zero when the infected population is zero, and the disease cannot persist.

For the moderate climate regions, all districts are assigned ACT combined with LLIN at $60 \%$ coverage in the first year, followed by ACT in combination with either LLIN or IRS at $60 \%$ coverage in subsequent years.

The sequence of interventions assigned in the wet regions at first glance appears more interesting. First, note that only low distribution cost districts, along with only two medium distribution cost and one high distribution cost districts, receive any intervention during the first year. 126 high distribution cost districts never receive any intervention in any of the 5 years. This is likely due to the budget constraint forcing the model to prioritize eliminating malaria in the dry climate regions during year 1 and leaving the harder-to-access wet regions largely untreated. In those wet districts receiving interventions, the chosen interventions are primarily LLIN with ACT at $60 \%$ coverage, but as Table 3 shows, these interventions do little to reduce the prevalence of malaria in the population. An apparent steady-state consists of $10 \%$ of the population in the infected state even after several years of $60 \%$ coverage of LLIN with ACT. Thus, it can be inferred that combating malaria in the wet regions is not possible with the interventions considered at coverage percentages up to $60 \%$. As will be shown later, increasing the maximum coverage to $80 \%$ is necessary for reducing malaria in wet regions.

\section{Effect of treatment efficacy}

The sequence of interventions allocated in the nine geographic regions under the optimistic and pessimistic efficacy scenarios, in which the disease transmission parameter values for the treated class are adjusted up or down by $30 \%$, can also be examined. The optimistic case is depicted in Fig. 2, with the full set of results given in Table 4 , and the results for the pessimistic case are given in Fig. 3 and Table 5.

In the optimistic case, note a reduction in person-days of malaria infection from 4.506 billion to 2.977 billion, or $34 \%$. In year 1 , the model focuses on eradicating (subject to rounding error) malaria in the dry and moderate climate regions by allocating LLIN, ACT or the two in combination. All but seven of the 1,500 wet climate districts receive no intervention in year 1 . In subsequent years, the wet climate districts receive $60 \%$ coverage of LLIN with ACT, and ACT with IRS, with a handful of wet climate districts receiving IPT or no intervention during years 1 and 2. Although it appears that the dry and moderate regions are also receiving interventions during years 2 through 5 , this is an artifact of the optimization model: once the infectious population is driven to zero, there is no value in distributing further interventions; the model is allocating interventions in these regions simply to use up the available budget. Moreover, the prevalence of malaria in the wet regions appears to stabilize around $10 \%$ in year 5 . This is further indication that $60 \%$ coverage is not sufficient to diminish malaria prevalence in the wet regions, even if the interventions are assumed to be highly effective.

In the pessimistic case, note an increase in person-days of malaria infection from 4.506 billion to 5.080 billion, or $13 \%$. In year 1 , resources are focused on rapidly reducing infections in the dry regions, by allocating $60 \%$ coverage of ACT; remaining resources in year 1 are focused on the moderate climate regions. In subsequent years, the moderate regions receive $60 \%$ coverage of ACT combined with either IRS or LLIN; the remaining budget is used 
Table 3 Optimal 5-year (Y1 through Y5) sequences of interventions for the baseline efficacy scenario

\begin{tabular}{|c|c|c|c|c|c|c|c|}
\hline $\begin{array}{l}\text { Geographic } \\
\text { region }\end{array}$ & $\begin{array}{l}\text { Number of } \\
\text { districts }\end{array}$ & $\begin{array}{l}\text { Initial } \\
\text { population state }\end{array}$ & $\begin{array}{l}\text { Y1 intervention } \\
\text { (end pop. state) }\end{array}$ & $\begin{array}{l}\text { Y2 intervention } \\
\text { (end pop. state) }\end{array}$ & $\begin{array}{l}\text { Y3 intervention } \\
\text { (end pop. state) }\end{array}$ & $\begin{array}{l}\text { Y4 intervention } \\
\text { (end pop. state) }\end{array}$ & $\begin{array}{l}\text { Y5 intervention } \\
\text { (end pop. state) }\end{array}$ \\
\hline$(D, L)$ & 500 & $(60,15,25)$ & $\begin{array}{l}\text { АСТ } 60 \% \\
(90,0,10)\end{array}$ & $\begin{array}{l}\text { None } \\
(95,0,5)\end{array}$ & $\begin{array}{l}\text { None } \\
(100,0,0)\end{array}$ & $\begin{array}{l}\text { None } \\
(100,0,0)\end{array}$ & $\begin{array}{l}\text { None } \\
(100,0,0)\end{array}$ \\
\hline$(\mathrm{D}, \mathrm{M})$ & 500 & $(60,15,25)$ & $\begin{array}{l}\text { АСТ } 60 \% \\
(90,0,10)\end{array}$ & $\begin{array}{l}\text { None } \\
(95,0,5)\end{array}$ & $\begin{array}{l}\text { None } \\
(100,0,0)\end{array}$ & $\begin{array}{l}\text { None } \\
(100,0,0)\end{array}$ & $\begin{array}{l}\text { None } \\
(100,0,0)\end{array}$ \\
\hline$(\mathrm{D}, \mathrm{H})$ & 500 & $(60,15,25)$ & $\begin{array}{l}\text { АСТ } 60 \% \\
(90,0,10)\end{array}$ & $\begin{array}{l}\text { None } \\
(95,0,5)\end{array}$ & $\begin{array}{l}\text { None } \\
(100,0,0)\end{array}$ & $\begin{array}{l}\text { None } \\
(100,0,0)\end{array}$ & $\begin{array}{l}\text { None } \\
(100,0,0)\end{array}$ \\
\hline$(M, L)$ & 500 & $(15,15,70)$ & $\begin{array}{l}\text { LLIN_ACT } 60 \% \\
(65,5,30)\end{array}$ & $\begin{array}{l}\text { ACT_IRS } 60 \% \\
(80,5,15)\end{array}$ & $\begin{array}{l}\text { ACT_IRS } 60 \% \\
(85,5,10)\end{array}$ & $\begin{array}{l}\text { ACT_IRS } 60 \% \\
(85,5,10)\end{array}$ & $\begin{array}{l}\text { ACT_IRS } 60 \% \\
(85,5,10)\end{array}$ \\
\hline$(M, M)$ & 500 & $(15,15,70)$ & $\begin{array}{l}\text { LLIN_ACT } 60 \% \\
(65,5,30)\end{array}$ & $\begin{array}{l}\text { ACT_IRS } 60 \% \\
(80,5,15)\end{array}$ & $\begin{array}{l}\text { ACT_IRS } 60 \% \\
(85,5,10)\end{array}$ & $\begin{array}{l}\text { ACT_IRS } 60 \% \\
(85,5,10)\end{array}$ & $\begin{array}{l}\text { LLIN_ACT } 60 \% \\
(75,10,15)\end{array}$ \\
\hline$(\mathrm{M}, \mathrm{H})$ & 500 & $(15,15,70)$ & $\begin{array}{l}\text { LLIN_ACT } 60 \% \\
(65,5,30)\end{array}$ & $\begin{array}{l}\text { ACT_IRS } 60 \% \\
(80,5,15)\end{array}$ & $\begin{array}{l}\text { ACT_IRS } 60 \% \\
(85,5,10)\end{array}$ & $\begin{array}{l}\text { ACT_IRS } 60 \% \\
(85,5,10)\end{array}$ & $\begin{array}{l}\text { LLIN_ACT } 60 \% \\
(75,10,15)\end{array}$ \\
\hline$(W, L)$ & 395 & $(10,15,75)$ & $\begin{array}{l}\text { LLIN_ACT } 20 \% \\
(25,10,65)\end{array}$ & $\begin{array}{l}\text { ACT_IRS } 60 \% \\
(65,5,30)\end{array}$ & $\begin{array}{l}\text { LLIN_ACT } 60 \% \\
(60,10,30)\end{array}$ & $\begin{array}{l}\text { LLIN_ACT } 60 \% \\
(60,10,30)\end{array}$ & $\begin{array}{l}\text { LLIN_ACT } 60 \% \\
(60,10,30)\end{array}$ \\
\hline$(W, L)$ & 105 & $(10,15,75)$ & $\begin{array}{l}\text { LLIN_ACT } 60 \% \\
(60,5,35)\end{array}$ & $\begin{array}{l}\text { LLIN_ACT } 60 \% \\
(60,10,30)\end{array}$ & $\begin{array}{l}\text { LLIN_ACT } 60 \% \\
(60,10,30)\end{array}$ & $\begin{array}{l}\text { LLIN_ACT } 60 \% \\
(60,10,30)\end{array}$ & $\begin{array}{l}\text { LLIN_ACT } 60 \% \\
(60,10,30)\end{array}$ \\
\hline$(\mathrm{W}, \mathrm{M})$ & 276 & $(10,15,75)$ & $\begin{array}{l}\text { None } \\
(10,15,75)\end{array}$ & $\begin{array}{l}\text { LLIN_ACT } 60 \% \\
(60,5,35)\end{array}$ & $\begin{array}{l}\text { LLIN_ACT } 60 \% \\
(60,10,30)\end{array}$ & $\begin{array}{l}\text { LLIN_ACT } 60 \% \\
(60,10,30)\end{array}$ & $\begin{array}{l}\text { LLIN_ACT } 60 \% \\
(60,10,30)\end{array}$ \\
\hline$(\mathrm{W}, \mathrm{M})$ & 136 & $(10,15,75)$ & $\begin{array}{l}\text { None } \\
(10,15,75)\end{array}$ & $\begin{array}{l}\text { LLIN_ACT } 20 \% \\
(25,10,65)\end{array}$ & $\begin{array}{l}\text { ACT_IRS } 60 \% \\
(65,5,30)\end{array}$ & $\begin{array}{l}\text { LLIN_ACT } 60 \% \\
(60,10,30)\end{array}$ & $\begin{array}{l}\text { LLIN_ACT } 60 \% \\
(60,10,30)\end{array}$ \\
\hline$(\mathrm{W}, \mathrm{M})$ & 59 & $(10,15,75)$ & $\begin{array}{l}\text { None } \\
(10,15,75)\end{array}$ & $\begin{array}{l}\text { None } \\
(10,15,75)\end{array}$ & $\begin{array}{l}\text { LLIN_ACT } 60 \% \\
(60,5,35)\end{array}$ & $\begin{array}{l}\text { LLIN_ACT } 60 \% \\
(60,10,30)\end{array}$ & $\begin{array}{l}\text { LLIN_ACT } 60 \% \\
(60,10,30)\end{array}$ \\
\hline$(\mathrm{W}, \mathrm{M})$ & 22 & $(10,15,75)$ & $\begin{array}{l}\text { None } \\
(10,15,75)\end{array}$ & $\begin{array}{l}\text { None } \\
(10,15,75)\end{array}$ & $\begin{array}{l}\text { None } \\
(10,15,75)\end{array}$ & $\begin{array}{l}\text { LLIN } 20 \% \\
(25,10,65)\end{array}$ & $\begin{array}{l}\text { LLIN_ACT } 60 \% \\
(55,10,35)\end{array}$ \\
\hline$(\mathrm{W}, \mathrm{M})$ & 3 & $(10,15,75)$ & $\begin{array}{l}\text { None } \\
(10,15,75)\end{array}$ & $\begin{array}{l}\text { None } \\
(10,15,75)\end{array}$ & $\begin{array}{l}\text { IPT } 40 \% \\
(10,15,75)\end{array}$ & $\begin{array}{l}\text { LLIN } 20 \% \\
(25,10,65)\end{array}$ & $\begin{array}{l}\text { LLIN_ACT } 60 \% \\
(55,10,35)\end{array}$ \\
\hline$(\mathrm{W}, \mathrm{M})$ & 2 & $(10,15,75)$ & $\begin{array}{l}\text { None } \\
(10,15,75)\end{array}$ & $\begin{array}{l}\text { IPT } 40 \% \\
(10,15,75)\end{array}$ & $\begin{array}{l}\text { LLIN_ACT } 60 \% \\
(60,5,35)\end{array}$ & $\begin{array}{l}\text { LLIN_ACT } 60 \% \\
(60,10,30)\end{array}$ & $\begin{array}{l}\text { LLIN_ACT } 60 \% \\
(60,10,30)\end{array}$ \\
\hline$(\mathrm{W}, \mathrm{M})$ & 1 & $(10,15,75)$ & $\begin{array}{l}\text { IPT } 20 \% \\
(10,15,75)\end{array}$ & $\begin{array}{l}\text { LLIN_ACT } 60 \% \\
(60,5,35)\end{array}$ & $\begin{array}{l}\text { LLIN_ACT } 60 \% \\
(60,10,30)\end{array}$ & $\begin{array}{l}\text { LLIN_ACT } 60 \% \\
(60,10,30)\end{array}$ & $\begin{array}{l}\text { LLIN_ACT } 60 \% \\
(60,10,30)\end{array}$ \\
\hline$(\mathrm{W}, \mathrm{M})$ & 1 & $(10,15,75)$ & $\begin{array}{l}\text { IPT } 40 \% \\
(10,15,75)\end{array}$ & $\begin{array}{l}\text { LLIN_ACT } 60 \% \\
(60,5,35)\end{array}$ & $\begin{array}{l}\text { LLIN_ACT } 60 \% \\
(60,10,30)\end{array}$ & $\begin{array}{l}\text { LLIN_ACT } 60 \% \\
(60,10,30)\end{array}$ & $\begin{array}{l}\text { LLIN_ACT } 60 \% \\
(60,10,30)\end{array}$ \\
\hline$(\mathrm{W}, \mathrm{H})$ & 371 & $(10,15,75)$ & $\begin{array}{l}\text { None } \\
(10,15,75)\end{array}$ & $\begin{array}{l}\text { None } \\
(10,15,75)\end{array}$ & $\begin{array}{l}\text { None } \\
(10,15,75)\end{array}$ & $\begin{array}{l}\text { None } \\
(10,15,75)\end{array}$ & $\begin{array}{l}\text { LLIN_ACT } 60 \% \\
(60,5,35)\end{array}$ \\
\hline$(\mathrm{W}, \mathrm{H})$ & 126 & $(10,15,75)$ & $\begin{array}{l}\text { None } \\
(10,15,75)\end{array}$ & $\begin{array}{l}\text { None } \\
(10,15,75)\end{array}$ & $\begin{array}{l}\text { None } \\
(10,15,75)\end{array}$ & $\begin{array}{l}\text { None } \\
(10,15,75)\end{array}$ & $\begin{array}{l}\text { None } \\
(10,15,75)\end{array}$ \\
\hline$(\mathrm{W}, \mathrm{H})$ & 1 & $(10,15,75)$ & $\begin{array}{l}\text { None } \\
(10,15,75)\end{array}$ & $\begin{array}{l}\text { None } \\
(10,15,75)\end{array}$ & $\begin{array}{l}\text { None } \\
(10,15,75)\end{array}$ & $\begin{array}{l}\text { None } \\
(10,15,75)\end{array}$ & $\begin{array}{l}\text { IPT } 40 \% \\
(10,15,75)\end{array}$ \\
\hline$(\mathrm{W}, \mathrm{H})$ & 1 & $(10,15,75)$ & $\begin{array}{l}\text { None } \\
(10,15,75)\end{array}$ & $\begin{array}{l}\text { None } \\
(10,15,75)\end{array}$ & $\begin{array}{l}\text { IPT } 40 \% \\
(10,15,75)\end{array}$ & $\begin{array}{l}\text { None } \\
(10,15,75)\end{array}$ & $\begin{array}{l}\text { LLIN_ACT } 60 \% \\
(60,5,35)\end{array}$ \\
\hline$(\mathrm{W}, \mathrm{H})$ & 1 & $(10,15,75)$ & $\begin{array}{l}\text { IPT } 40 \% \\
(10,15,75)\end{array}$ & $\begin{array}{l}\text { IPT } 40 \% \\
(10,15,75)\end{array}$ & $\begin{array}{l}\text { IPT } 40 \% \\
(10,15,75)\end{array}$ & $\begin{array}{l}\text { IPT } 20 \% \\
(10,15,75)\end{array}$ & $\begin{array}{l}\text { LLIN_ACT } 60 \% \\
(60,5,35)\end{array}$ \\
\hline
\end{tabular}

Geographic region refers to the climate region and distribution cost pair, where the climate region is dry (D), moderate (M) or wet (W), and the distribution cost is low $(\mathrm{L})$, medium $(\mathrm{M})$ or high $(\mathrm{H})$. Number of districts refers to the number of districts that were assigned a given trajectory. Initial population state is the starting $(S, I, R)$ percentages of the region; the end population state for a given year is the resulting $(S, I, R)$ state after distributing the corresponding intervention. The total persondays of malaria infection in this scenario is 4.506 billion 


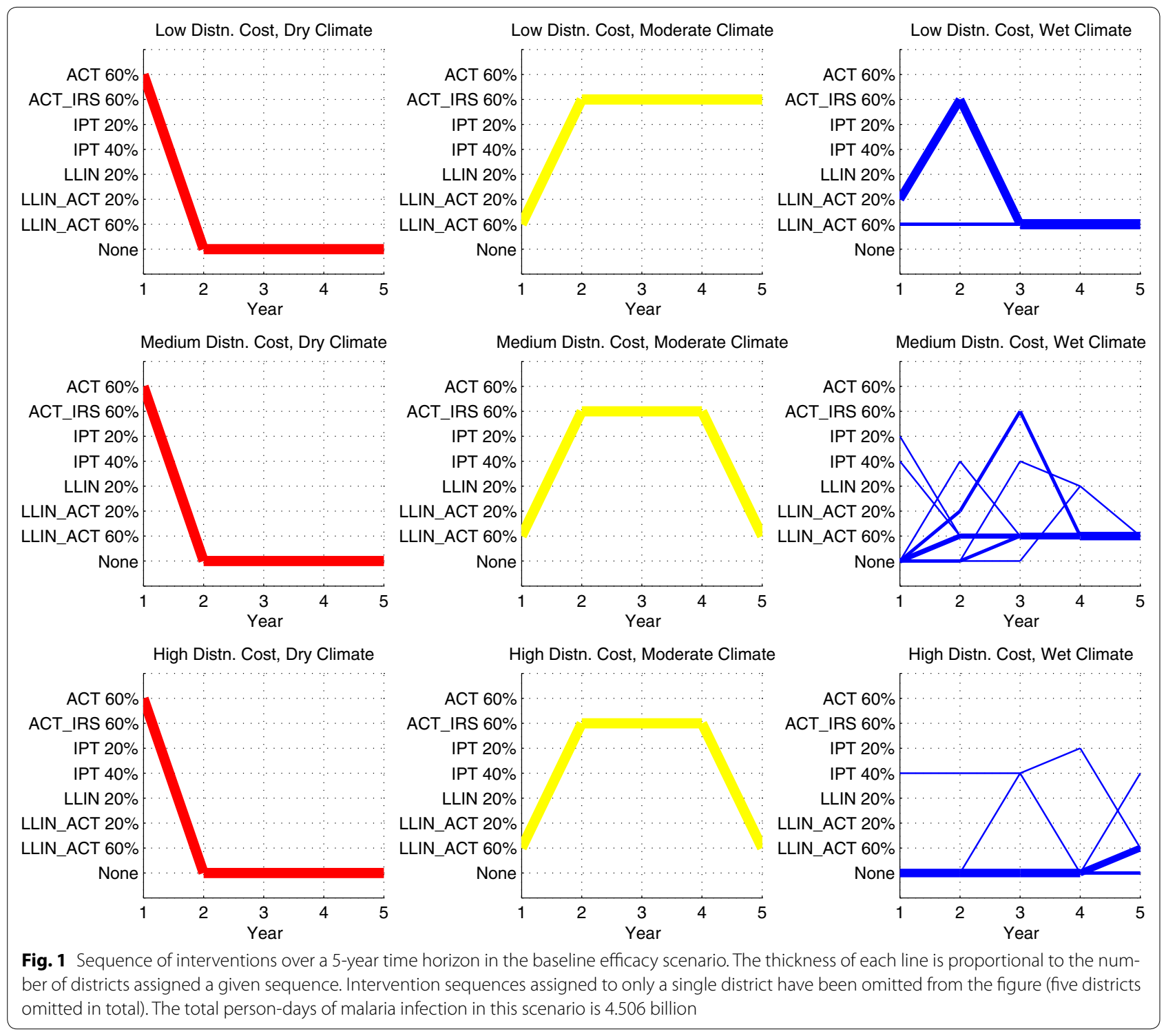

to allocate a variety of interventions in the wet regions. The takeaway message here is that to minimize persondays of malaria infection, the model chooses to focus resources on the dry and moderate climate regions; any remaining budget is allocated to the wet regions.

\section{Effect of coverage}

If a maximum coverage of $80 \%$ (including both distribution and compliance) is attainable, the results change dramatically. Table 6 gives the sequence of interventions assuming a baseline efficacy and possible coverage levels of $40 \%, 60$ and $80 \%$ (rather than 20, 40 and $60 \%$ used earlier), and using the same annual budget of 33.75 million USD. In all geographic regions, the infected population is driven to zero within 2 years, indicating that malaria is effectively eradicated (at least subject to rounding at a resolution of $5 \%$ ). Thus, achieving high coverage is crucial to rapid eradication of malaria, even with the annual budget held constant. Although intervention costs rise in proportion to the treatment coverage, the fixed budget is able to achieve markedly lower persondays of malaria infection when $80 \%$ coverage is achievable as opposed to only $60 \%$ (1.139 billion person days, as opposed to 4.506 billion person days,) although some of this effect is likely due to rounding at resolution $5 \%$. Thus, giving a smaller number of cities a higher coverage is more effective than giving a larger number of cities a lower coverage. Moreover, it is only when $80 \%$ coverage is attainable that the prevalence of malaria is reduced in the wet climate regions. 


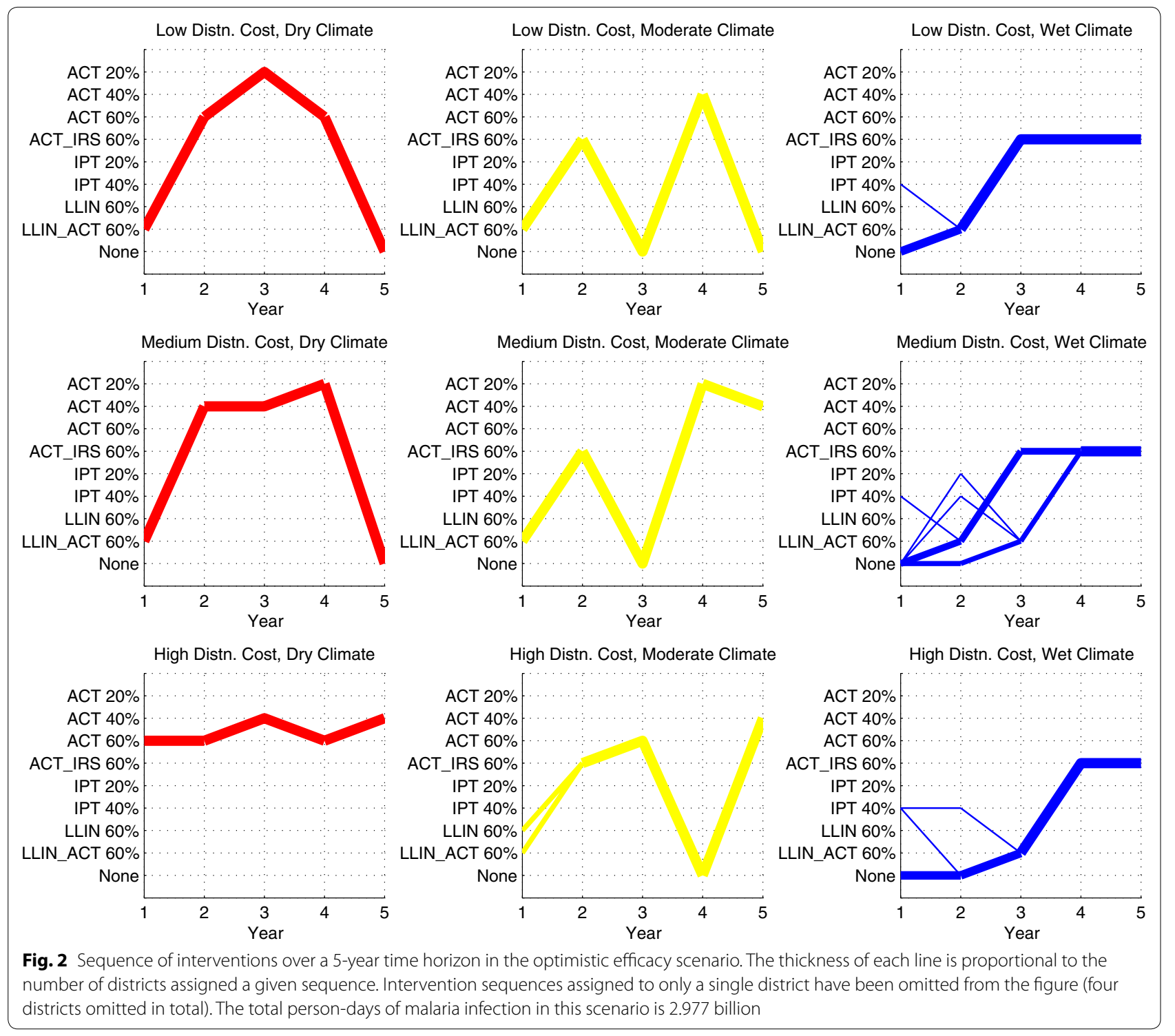

Because the $80 \%$ coverage eradicates malaria so quickly in the model, the interpretation of the 5-year model results becomes less interesting. For this reason, the remainder of the results will be presented using the original coverage percentages of 20,40 and $60 \%$, except where otherwise indicated.

\section{Effect of budget}

Previous work by Dimitrov et al. suggested that increasing the budget would decrease malaria deaths roughly linearly up to a critical budget value, after which there would be diminishing marginal benefit to additional budget expenditures [11]. Using the baseline efficacy scenario, the optimization problem was solved sequentially for budgets ranging from 15 million USD to 155 million
USD in increments of 10 million USD, and person-days of malaria infection was plotted against budget. As seen in Fig. 4, the model's results are consistent with Dimitrov et al. [11]. The person-days of malaria infection decrease linearly with an increase in budget until roughly 55 million USD, after which diminishing marginal returns on budget increases are observed. Moreover, beyond a budget of 85 million USD, there can be no further reduction in person-days of malaria infection. Also shown in Fig. 4 is the plot of person-days of malaria infection in the baseline scenario when coverage up to $80 \%$ is attainable. The graph exhibits the same general shape, but with substantially lower values for the person-days of malaria infection. Moreover, even with a very large budget, $60 \%$ coverage cannot achieve the low prevalence of malaria 
Table 4 Optimal 5-year (Y1 through Y5) sequences of interventions for the optimistic efficacy scenario

\begin{tabular}{|c|c|c|c|c|c|c|c|}
\hline $\begin{array}{l}\text { Geographic } \\
\text { region }\end{array}$ & $\begin{array}{l}\text { Number of } \\
\text { districts }\end{array}$ & $\begin{array}{l}\text { Initial } \\
\text { population state }\end{array}$ & $\begin{array}{l}\text { Y1 intervention } \\
\text { (end pop. state) }\end{array}$ & $\begin{array}{l}\text { Y2 intervention } \\
\text { (end pop. state) }\end{array}$ & $\begin{array}{l}\text { Y3 intervention } \\
\text { (end pop. state) }\end{array}$ & $\begin{array}{l}\text { Y4 intervention } \\
\text { (end pop. state) }\end{array}$ & $\begin{array}{l}\text { Y5 intervention } \\
\text { (end pop. state) }\end{array}$ \\
\hline$(D, L)$ & 500 & $(60,15,25)$ & $\begin{array}{l}\text { LLIN_ACT } 60 \% \\
(90,0,10)\end{array}$ & $\begin{array}{l}\text { АСТ } 60 \% \\
(95,0,5)\end{array}$ & $\begin{array}{l}\text { АСТ } 20 \% \\
(100,0,0)\end{array}$ & $\begin{array}{l}\text { АСТ } 60 \% \\
(100,0,0)\end{array}$ & $\begin{array}{l}\text { None } \\
(100,0,0)\end{array}$ \\
\hline$(\mathrm{D}, \mathrm{M})$ & 500 & $(60,15,25)$ & $\begin{array}{l}\text { LLIN_ACT } 60 \% \\
(90,0,10)\end{array}$ & $\begin{array}{l}\text { ACT } 40 \% \\
(95,0,5)\end{array}$ & $\begin{array}{l}\text { АCT } 40 \% \\
(100,0,0)\end{array}$ & $\begin{array}{l}\text { АСТ } 20 \% \\
(100,0,0)\end{array}$ & $\begin{array}{l}\text { None } \\
(100,0,0)\end{array}$ \\
\hline$(D, H)$ & 500 & $(60,15,25)$ & $\begin{array}{l}\text { ACT } 60 \% \\
(85,5,10)\end{array}$ & $\begin{array}{l}\text { АCT } 60 \% \\
(95,0,5)\end{array}$ & $\begin{array}{l}\text { ACT } 40 \% \\
(100,0,0)\end{array}$ & $\begin{array}{l}\text { АСТ } 60 \% \\
(100,0,0)\end{array}$ & $\begin{array}{l}\text { АCT } 40 \% \\
(100,0,0)\end{array}$ \\
\hline$(M, L)$ & 500 & $(15,15,70)$ & $\begin{array}{l}\text { LLIN_ACT } 60 \% \\
(65,5,30)\end{array}$ & $\begin{array}{l}\text { ACT_IRS } 60 \% \\
(90,0,10)\end{array}$ & $\begin{array}{l}\text { None } \\
(95,0,5)\end{array}$ & $\begin{array}{l}\text { ACT } 40 \% \\
(100,0,0)\end{array}$ & $\begin{array}{l}\text { None } \\
(100,0,0)\end{array}$ \\
\hline$(M, M)$ & 500 & $(15,15,70)$ & $\begin{array}{l}\text { LLIN_ACT } 60 \% \\
(65,5,30)\end{array}$ & $\begin{array}{l}\text { ACT_IRS } 60 \% \\
(90,0,10)\end{array}$ & $\begin{array}{l}\text { None } \\
(95,0,5)\end{array}$ & $\begin{array}{l}\text { АСТ } 20 \% \\
(100,0,0)\end{array}$ & $\begin{array}{l}\text { АCТ } 40 \% \\
(100,0,0)\end{array}$ \\
\hline$(\mathrm{M}, \mathrm{H})$ & 266 & $(15,15,70)$ & $\begin{array}{l}\text { LLIN_ACT } 60 \% \\
(65,5,30)\end{array}$ & $\begin{array}{l}\text { ACT_IRS } 60 \% \\
(90,0,10)\end{array}$ & $\begin{array}{l}\text { АСТ } 60 \% \\
(95,0,5)\end{array}$ & $\begin{array}{l}\text { None } \\
(100,0,0)\end{array}$ & $\begin{array}{l}\text { ACT } 40 \% \\
(100,0,0)\end{array}$ \\
\hline$(\mathrm{M}, \mathrm{H})$ & 234 & $(15,15,70)$ & $\begin{array}{l}\text { LLIN } 60 \% \\
(60,5,35)\end{array}$ & $\begin{array}{l}\text { ACT_IRS } 60 \% \\
(90,0,10)\end{array}$ & $\begin{array}{l}\text { АСТ } 60 \% \\
(95,0,5)\end{array}$ & $\begin{array}{l}\text { None } \\
(100,0,0)\end{array}$ & $\begin{array}{l}\text { ACT } 40 \% \\
(100,0,0)\end{array}$ \\
\hline$(W, L)$ & 497 & $(10,15,75)$ & $\begin{array}{l}\text { None } \\
(10,15,75)\end{array}$ & $\begin{array}{l}\text { LLIN_ACT } 60 \% \\
(60,5,35)\end{array}$ & $\begin{array}{l}\text { ACT_IRS } 60 \% \\
(80,5,15)\end{array}$ & $\begin{array}{l}\text { ACT_IRS } 60 \% \\
(75,10,15)\end{array}$ & $\begin{array}{l}\text { ACT_IRS } 60 \% \\
(75,10,15)\end{array}$ \\
\hline$(W, L)$ & 3 & $(10,15,75)$ & $\begin{array}{l}\text { IPT } 40 \% \\
(10,15,75)\end{array}$ & $\begin{array}{l}\text { LLIN_ACT } 60 \% \\
(60,5,35)\end{array}$ & $\begin{array}{l}\text { ACT_IRS } 60 \% \\
(80,5,15)\end{array}$ & $\begin{array}{l}\text { ACT_IRS } 60 \% \\
(75,10,15)\end{array}$ & $\begin{array}{l}\text { ACT_IRS } 60 \% \\
(75,10,15)\end{array}$ \\
\hline$(\mathrm{W}, \mathrm{M})$ & 324 & $(10,15,75)$ & $\begin{array}{l}\text { None } \\
(10,15,75)\end{array}$ & $\begin{array}{l}\text { LLIN_ACT } 60 \% \\
(60,5,35)\end{array}$ & $\begin{array}{l}\text { ACT_IRS } 60 \% \\
(80,5,15)\end{array}$ & $\begin{array}{l}\text { ACT_IRS } 60 \% \\
(75,10,15)\end{array}$ & $\begin{array}{l}\text { ACT_IRS } 60 \% \\
(75,10,15)\end{array}$ \\
\hline$(\mathrm{W}, \mathrm{M})$ & 172 & $(10,15,75)$ & $\begin{array}{l}\text { None } \\
(10,15,75)\end{array}$ & $\begin{array}{l}\text { None } \\
(10,15,75)\end{array}$ & $\begin{array}{l}\text { LLIN_ACT } 60 \% \\
(60,5,35)\end{array}$ & $\begin{array}{l}\text { ACT_IRS } 60 \% \\
(80,5,15)\end{array}$ & $\begin{array}{l}\text { ACT_IRS } 60 \% \\
(75,10,15)\end{array}$ \\
\hline$(\mathrm{W}, \mathrm{M})$ & 2 & $(10,15,75)$ & $\begin{array}{l}\text { IPT } 40 \% \\
(10,15,75)\end{array}$ & $\begin{array}{l}\text { LLIN_ACT } 60 \% \\
(60,5,35)\end{array}$ & $\begin{array}{l}\text { ACT_IRS } 60 \% \\
(80,5,15)\end{array}$ & $\begin{array}{l}\text { ACT_IRS } 60 \% \\
(75,10,15)\end{array}$ & $\begin{array}{l}\text { ACT_IRS } 60 \% \\
(75,10,15)\end{array}$ \\
\hline$(\mathrm{W}, \mathrm{M})$ & 1 & $(10,15,75)$ & $\begin{array}{l}\text { None } \\
(10,15,75)\end{array}$ & $\begin{array}{l}\text { IPT } 20 \% \\
(10,15,75)\end{array}$ & $\begin{array}{l}\text { LLIN_ACT } 60 \% \\
(60,5,35)\end{array}$ & $\begin{array}{l}\text { ACT_IRS } 60 \% \\
(80,5,15)\end{array}$ & $\begin{array}{l}\text { ACT_IRS } 60 \% \\
(75,10,15)\end{array}$ \\
\hline$(\mathrm{W}, \mathrm{M})$ & 1 & $(10,15,75)$ & $\begin{array}{l}\text { None } \\
(10,15,75)\end{array}$ & $\begin{array}{l}\text { IPT } 40 \% \\
(10,15,75)\end{array}$ & $\begin{array}{l}\text { LLIN_ACT } 60 \% \\
(60,5,35)\end{array}$ & $\begin{array}{l}\text { ACT_IRS } 60 \% \\
(80,5,15)\end{array}$ & $\begin{array}{l}\text { ACT_IRS } 60 \% \\
(75,10,15)\end{array}$ \\
\hline$(W, H)$ & 498 & $(10,15,75)$ & $\begin{array}{l}\text { None } \\
(10,15,75)\end{array}$ & $\begin{array}{l}\text { None } \\
(10,15,75)\end{array}$ & $\begin{array}{l}\text { LLIN_ACT } 60 \% \\
(60,5,35)\end{array}$ & $\begin{array}{l}\text { ACT_IRS } 60 \% \\
(80,5,15)\end{array}$ & $\begin{array}{l}\text { ACT_IRS } 60 \% \\
(75,10,15)\end{array}$ \\
\hline$(\mathrm{W}, \mathrm{H})$ & 1 & $(10,15,75)$ & $\begin{array}{l}\text { IPT } 40 \% \\
(10,15,75)\end{array}$ & $\begin{array}{l}\text { None } \\
(10,15,75)\end{array}$ & $\begin{array}{l}\text { LLIN_ACT } 60 \% \\
(60,5,35)\end{array}$ & $\begin{array}{l}\text { ACT_IRS } 60 \% \\
(80,5,15)\end{array}$ & $\begin{array}{l}\text { ACT_IRS } 60 \% \\
(75,10,15)\end{array}$ \\
\hline$(\mathrm{W}, \mathrm{H})$ & 1 & $(10,15,75)$ & $\begin{array}{l}\text { IPT } 40 \% \\
(10,15,75)\end{array}$ & $\begin{array}{l}\text { IPT } 40 \% \\
(10,15,75)\end{array}$ & $\begin{array}{l}\text { LLIN_ACT } 60 \% \\
(60,5,35)\end{array}$ & $\begin{array}{l}\text { ACT_IRS } 60 \% \\
(80,5,15)\end{array}$ & $\begin{array}{l}\text { ACT_IRS } 60 \% \\
(75,10,15)\end{array}$ \\
\hline
\end{tabular}

Geographic region refers to the climate region and distribution cost pair, where the climate region is dry (D), moderate (M) or wet (W), and the distribution cost is low $(\mathrm{L})$, medium $(\mathrm{M})$ or high $(\mathrm{H})$. Number of districts refers to the number of districts that were assigned a given trajectory. Initial population state is the starting $(S, I, R)$ percentages of the region; the end population state for a given year is the resulting $(S, I, R)$ state after distributing the corresponding intervention. The total persondays of malaria infection in this scenario is 2.977 billion

infection that $80 \%$ coverage can achieve with even a small budget.

Additionally, the qualitative change in the interventions chosen at different budget levels is evident in Fig. 5. When the budget is 15 million USD, for instance, most districts receive no intervention in most years. Those that do receive $60 \%$ coverage of ACT, either alone or in combination with either IRS or LLIN, or $40 \%$ coverage of IPT. (Although not shown in Fig. 5, the raw results from the simulation reveal that the dry regions receive interventions in year 1 , which effectively eradicates malaria in those regions; most of the moderate climate regions receive interventions in most years, with a cluster of high distribution cost districts receiving no intervention in any of the 5 years; and the wet regions typically receive no intervention in most years). When the budget is 85 million USD, Fig. 5 shows that the number of districts receiving no intervention in some year drops sharply. (A closer look at the raw results reveals that all regions receive the maximum 


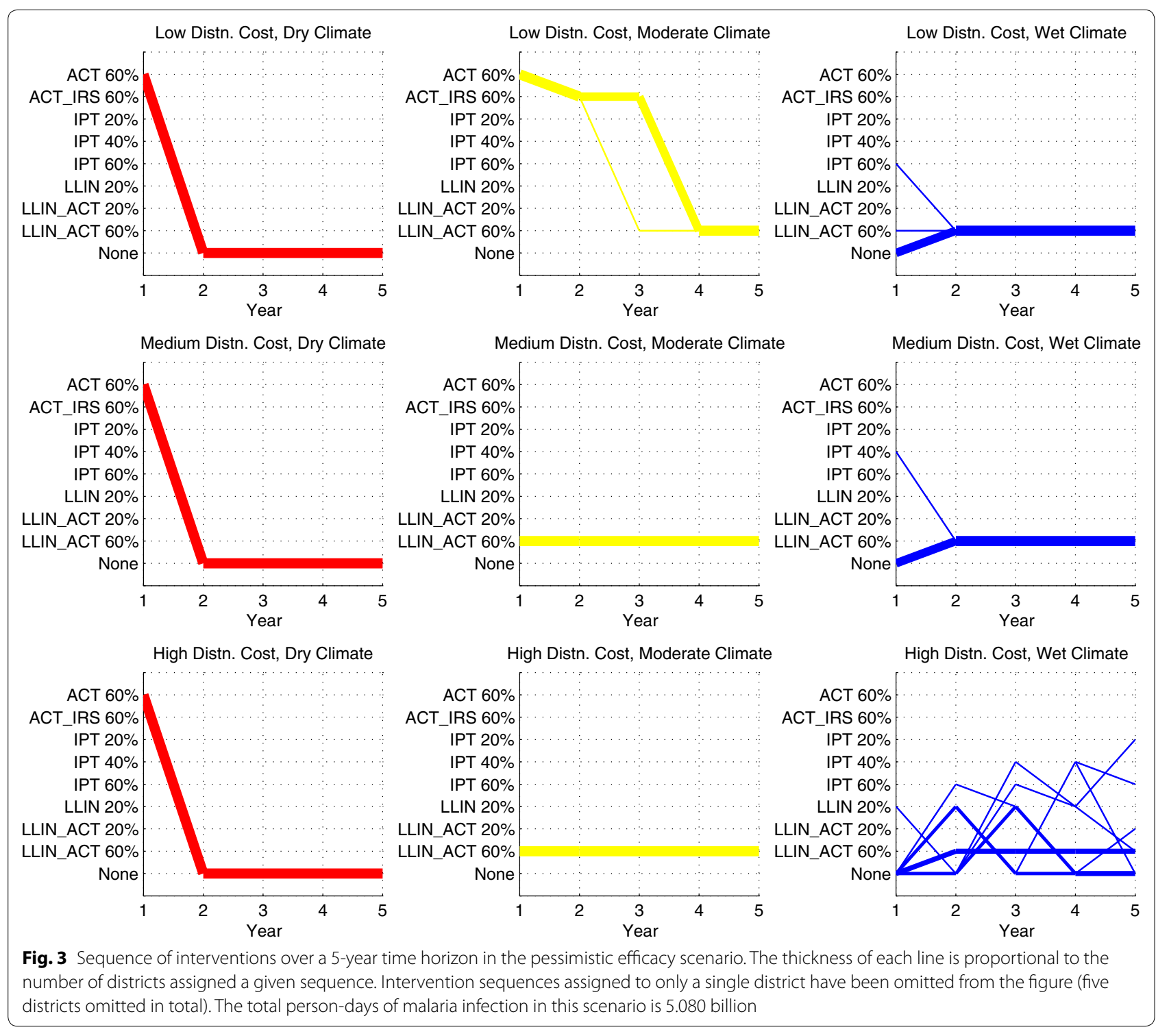

of $60 \%$ coverage of ACT in combination with IRS in all years, except for the dry regions, which receive no intervention in years 2 through 5 after malaria has been effectively eradicated).

Figure 6 shows the percentage of the total population that is in the infected class at the end of each of the 5 years, when the annual budget is 15 million USD as compared to 85 million USD. A 15 million USD annual budget achieves a drop from $15 \%$ infected to around $8 \%$ infected in steady state. An 85 million USD annual budget achieves an initial drop to around $3 \%$ infected, which levels out to $5 \%$ infected in steady-state. (Note that this contrasts with the results shown previously in Table 6 where if coverage of $80 \%$ is attainable, malaria is eradicated with only a 33.75 million USD budget).

\section{Role of vaccine}

The authors were surprised to observe that in all of the simulations across geographic regions, efficacy scenarios, maximum coverage, and budgets, the vaccine is almost never chosen, either alone or in combination with IPT. Although the annual cost per treated person is quite high (20.66 USD), the fact that it is distributed only to children under the age of four, comprising an estimated $14.6 \%$ of the population, makes its district-wide cost on par with that of the other interventions. The model can be used to understand under what conditions a malaria vaccine would be a cost-effective intervention by systematically lowering its cost and increasing its efficacy. Specifically, the optimization model was solved on all combinations of $b_{t}=0.001,0.005$, or $0.009, \gamma_{t}=\frac{1}{2}, \frac{1}{5.5}$, 
Table 5 Optimal 5-year (Y1 through Y5) sequences of interventions for the pessimistic efficacy scenario

\begin{tabular}{|c|c|c|c|c|c|c|c|}
\hline $\begin{array}{l}\text { Geographic } \\
\text { region }\end{array}$ & $\begin{array}{l}\text { Number of } \\
\text { districts }\end{array}$ & $\begin{array}{l}\text { Initial } \\
\text { population state }\end{array}$ & $\begin{array}{l}\text { Y1 intervention } \\
\text { (end pop. state) }\end{array}$ & $\begin{array}{l}\text { Y2 intervention } \\
\text { (end pop. state) }\end{array}$ & $\begin{array}{l}\text { Y3 intervention } \\
\text { (end pop. state) }\end{array}$ & $\begin{array}{l}\text { Y4 intervention } \\
\text { (end pop. state) }\end{array}$ & $\begin{array}{l}\text { Y5 intervention } \\
\text { (end pop. state) }\end{array}$ \\
\hline$(\mathrm{D}, \mathrm{L})$ & 500 & $(60,15,25)$ & $\begin{array}{l}\text { АСТ } 60 \% \\
(90,0,10)\end{array}$ & $\begin{array}{l}\text { None } \\
(95,0,5)\end{array}$ & $\begin{array}{l}\text { None } \\
(100,0,0)\end{array}$ & $\begin{array}{l}\text { None } \\
(100,0,0)\end{array}$ & $\begin{array}{l}\text { None } \\
(100,0,0)\end{array}$ \\
\hline$(\mathrm{D}, \mathrm{M})$ & 500 & $(60,15,25)$ & $\begin{array}{l}\text { АСТ } 60 \% \\
(90,0,10)\end{array}$ & $\begin{array}{l}\text { None } \\
(95,0,5)\end{array}$ & $\begin{array}{l}\text { None } \\
(100,0,0)\end{array}$ & $\begin{array}{l}\text { None } \\
(100,0,0)\end{array}$ & $\begin{array}{l}\text { None } \\
(100,0,0)\end{array}$ \\
\hline$(D, H)$ & 500 & $(60,15,25)$ & $\begin{array}{l}\text { АСТ } 60 \% \\
(90,0,10)\end{array}$ & $\begin{array}{l}\text { None } \\
(95,0,5)\end{array}$ & $\begin{array}{l}\text { None } \\
(100,0,0)\end{array}$ & $\begin{array}{l}\text { None } \\
(100,0,0)\end{array}$ & $\begin{array}{l}\text { None } \\
(100,0,0)\end{array}$ \\
\hline$(M, L)$ & 494 & $(15,15,70)$ & $\begin{array}{l}\text { АCT } 60 \% \\
(60,5,35)\end{array}$ & $\begin{array}{l}\text { ACT_IRS } 60 \% \\
(80,5,15)\end{array}$ & $\begin{array}{l}\text { ACT_IRS } 60 \% \\
(75,10,15)\end{array}$ & $\begin{array}{l}\text { LLIN_ACT } 60 \% \\
(70,10,20)\end{array}$ & $\begin{array}{l}\text { LLIN_ACT } 60 \% \\
(70,10,20)\end{array}$ \\
\hline$(M, L)$ & 6 & $(15,15,70)$ & $\begin{array}{l}\text { АСТ } 60 \% \\
(60,5,35)\end{array}$ & $\begin{array}{l}\text { ACT_IRS } 60 \% \\
(80,5,15)\end{array}$ & $\begin{array}{l}\text { LLIN_ACT } 60 \% \\
(75,10,15)\end{array}$ & $\begin{array}{l}\text { LLIN_ACT } 60 \% \\
(70,10,20)\end{array}$ & $\begin{array}{l}\text { LLIN_ACT } 60 \% \\
(70,10,20)\end{array}$ \\
\hline$(M, M)$ & 500 & $(15,15,70)$ & $\begin{array}{l}\text { LLIN_ACT } 60 \% \\
(65,5,30)\end{array}$ & $\begin{array}{l}\text { LLIN_ACT } 60 \% \\
(75,10,15)\end{array}$ & $\begin{array}{l}\text { LLIN_ACT } 60 \% \\
(70,10,20)\end{array}$ & $\begin{array}{l}\text { LLIN_ACT } 60 \% \\
(70,10,20)\end{array}$ & $\begin{array}{l}\text { LLIN_ACT } 60 \% \\
(70,10,20)\end{array}$ \\
\hline$(\mathrm{M}, \mathrm{H})$ & 500 & $(15,15,70)$ & $\begin{array}{l}\text { LLIN_ACT } 60 \% \\
(65,5,30)\end{array}$ & $\begin{array}{l}\text { LLIN_ACT } 60 \% \\
(75,10,15)\end{array}$ & $\begin{array}{l}\text { LLIN_ACT } 60 \% \\
(70,10,20)\end{array}$ & $\begin{array}{l}\text { LLIN_ACT } 60 \% \\
(70,10,20)\end{array}$ & $\begin{array}{l}\text { LLIN_ACT } 60 \% \\
(70,10,20)\end{array}$ \\
\hline$(\mathrm{W}, \mathrm{L})$ & 464 & $(10,15,75)$ & $\begin{array}{l}\text { None } \\
(10,15,75)\end{array}$ & $\begin{array}{l}\text { LLIN_ACT } 60 \% \\
(60,5,35)\end{array}$ & $\begin{array}{l}\text { LLIN_ACT } 60 \% \\
(60,10,30)\end{array}$ & $\begin{array}{l}\text { LLIN_ACT } 60 \% \\
(60,10,30)\end{array}$ & $\begin{array}{l}\text { LLIN_ACT } 60 \% \\
(60,10,30)\end{array}$ \\
\hline$(\mathrm{W}, \mathrm{L})$ & 35 & $(10,15,75)$ & $\begin{array}{l}\text { LLIN_ACT } 60 \% \\
(60,5,35)\end{array}$ & $\begin{array}{l}\text { LLIN_ACT } 60 \% \\
(60,10,30)\end{array}$ & $\begin{array}{l}\text { LLIN_ACT } 60 \% \\
(60,10,30)\end{array}$ & $\begin{array}{l}\text { LLIN_ACT } 60 \% \\
(60,10,30)\end{array}$ & $\begin{array}{l}\text { LLIN_ACT } 60 \% \\
(60,10,30)\end{array}$ \\
\hline$(W, L)$ & 1 & $(10,15,75)$ & $\begin{array}{l}\text { IPT } 60 \% \\
(10,15,75)\end{array}$ & $\begin{array}{l}\text { LLIN_ACT } 60 \% \\
(60,5,35)\end{array}$ & $\begin{array}{l}\text { LLIN_ACT } 60 \% \\
(60,10,30)\end{array}$ & $\begin{array}{l}\text { LLIN_ACT } 60 \% \\
(60,10,30)\end{array}$ & $\begin{array}{l}\text { LLIN_ACT } 60 \% \\
(60,10,30)\end{array}$ \\
\hline$(\mathrm{W}, \mathrm{M})$ & 499 & $(10,15,75)$ & $\begin{array}{l}\text { None } \\
(10,15,75)\end{array}$ & $\begin{array}{l}\text { LLIN_ACT } 60 \% \\
(60,5,35)\end{array}$ & $\begin{array}{l}\text { LLIN_ACT } 60 \% \\
(60,10,30)\end{array}$ & $\begin{array}{l}\text { LLIN_ACT } 60 \% \\
(60,10,30)\end{array}$ & $\begin{array}{l}\text { LLIN_ACT } 60 \% \\
(60,10,30)\end{array}$ \\
\hline$(\mathrm{W}, \mathrm{M})$ & 1 & $(10,15,75)$ & $\begin{array}{l}\text { IPT } 40 \% \\
(10,15,75)\end{array}$ & $\begin{array}{l}\text { LLIN_ACT } 60 \% \\
(60,5,35)\end{array}$ & $\begin{array}{l}\text { LLIN_ACT } 60 \% \\
(60,10,30)\end{array}$ & $\begin{array}{l}\text { LLIN_ACT } 60 \% \\
(60,10,30)\end{array}$ & $\begin{array}{l}\text { LLIN_ACT } 60 \% \\
(60,10,30)\end{array}$ \\
\hline$(\mathrm{W}, \mathrm{H})$ & 241 & $(10,15,75)$ & $\begin{array}{l}\text { None } \\
(10,15,75)\end{array}$ & $\begin{array}{l}\text { LLIN_ACT } 60 \% \\
(60,5,35)\end{array}$ & $\begin{array}{l}\text { LLIN_ACT } 60 \% \\
(60,10,30)\end{array}$ & $\begin{array}{l}\text { LLIN_ACT } 60 \% \\
(60,10,30)\end{array}$ & $\begin{array}{l}\text { LLIN_ACT } 60 \% \\
(60,10,30)\end{array}$ \\
\hline$(\mathrm{W}, \mathrm{H})$ & 140 & $(10,15,75)$ & $\begin{array}{l}\text { None } \\
(10,15,75)\end{array}$ & $\begin{array}{l}\text { None } \\
(10,15,75)\end{array}$ & $\begin{array}{l}\text { LLIN } 20 \% \\
(20,10,70)\end{array}$ & $\begin{array}{l}\text { None } \\
(5,15,80)\end{array}$ & $\begin{array}{l}\text { None } \\
(10,15,75)\end{array}$ \\
\hline$(\mathrm{W}, \mathrm{H})$ & 109 & $(10,15,75)$ & $\begin{array}{l}\text { None } \\
(10,15,75)\end{array}$ & $\begin{array}{l}\text { LLIN } 20 \% \\
(20,10,70)\end{array}$ & $\begin{array}{l}\text { None } \\
(5,15,80)\end{array}$ & $\begin{array}{l}\text { None } \\
(10,15,75)\end{array}$ & $\begin{array}{l}\text { None } \\
(10,15,75)\end{array}$ \\
\hline$(\mathrm{W}, \mathrm{H})$ & 3 & $(10,15,75)$ & $\begin{array}{l}\text { LLIN } 20 \% \\
(20,10,70)\end{array}$ & $\begin{array}{l}\text { None } \\
(5,15,80)\end{array}$ & $\begin{array}{l}\text { IPT } 40 \% \\
(10,15,75)\end{array}$ & $\begin{array}{l}\text { LLIN } 20 \% \\
(20,10,70)\end{array}$ & $\begin{array}{l}\text { LLIN_ACT } 60 \% \\
(55,10,35)\end{array}$ \\
\hline$(\mathrm{W}, \mathrm{H})$ & 2 & $(10,15,75)$ & $\begin{array}{l}\text { None } \\
(10,15,75)\end{array}$ & $\begin{array}{l}\text { IPT } 60 \% \\
(10,15,75)\end{array}$ & $\begin{array}{l}\text { LLIN } 20 \% \\
(20,10,70)\end{array}$ & $\begin{array}{l}\text { None } \\
(5,15,80)\end{array}$ & $\begin{array}{l}\text { None } \\
(10,15,75)\end{array}$ \\
\hline$(\mathrm{W}, \mathrm{H})$ & 2 & $(10,15,75)$ & $\begin{array}{l}\text { None } \\
(10,15,75)\end{array}$ & $\begin{array}{l}\text { LLIN } 20 \% \\
(20,10,70)\end{array}$ & $\begin{array}{l}\text { None } \\
(5,15,80)\end{array}$ & $\begin{array}{l}\text { IPT } 40 \% \\
(10,15,75)\end{array}$ & $\begin{array}{l}\text { IPT } 60 \% \\
(10,15,75)\end{array}$ \\
\hline$(W, H)$ & 1 & $(10,15,75)$ & $\begin{array}{l}\text { None } \\
(10,15,75)\end{array}$ & $\begin{array}{l}\text { None } \\
(10,15,75)\end{array}$ & $\begin{array}{l}\text { IPT } 60 \% \\
(10,15,75)\end{array}$ & $\begin{array}{l}\text { LLIN } 20 \% \\
(20,10,70)\end{array}$ & $\begin{array}{l}\text { IPT } 20 \% \\
(10,15,75)\end{array}$ \\
\hline$(\mathrm{W}, \mathrm{H})$ & 1 & $(10,15,75)$ & $\begin{array}{l}\text { None } \\
(10,15,75)\end{array}$ & $\begin{array}{l}\text { IPT } 60 \% \\
(10,15,75)\end{array}$ & $\begin{array}{l}\text { LLIN } 20 \% \\
(20,10,70)\end{array}$ & $\begin{array}{l}\text { None } \\
(5,15,80)\end{array}$ & $\begin{array}{l}\text { LLIN_ACT } 20 \% \\
(25,10,65)\end{array}$ \\
\hline$(\mathrm{W}, \mathrm{H})$ & 1 & $(10,15,75)$ & $\begin{array}{l}\text { None } \\
(10,15,75)\end{array}$ & $\begin{array}{l}\text { LLIN } 20 \% \\
(20,10,70)\end{array}$ & $\begin{array}{l}\text { None } \\
(5,15,80)\end{array}$ & $\begin{array}{l}\text { IPT } 40 \% \\
(10,15,75)\end{array}$ & $\begin{array}{l}\text { None } \\
(10,15,75)\end{array}$ \\
\hline
\end{tabular}

Geographic region refers to the climate region and distribution cost pair, where the climate region is dry (D), moderate (M) or wet (W), and the distribution cost is low $(\mathrm{L})$, medium $(\mathrm{M})$ or high $(\mathrm{H})$. Number of districts refers to the number of districts that were assigned a given trajectory. Initial population state is the starting $(S, I, R)$ percentages of the region; the end population state for a given year is the resulting $(S, I, R)$ state after distributing the corresponding intervention. The total persondays of malaria infection in this scenario is 5.080 billion

or $\frac{1}{30}$, and vaccine cost $=2,5,10$, or 20.66 USD per person annually. Preliminary analysis of these results showed little influence of either $b_{t}$ or $\gamma_{t}$ on the number of times vaccine was selected; for most combinations of $b_{t}$ and $\gamma_{t}$, vaccine will be frequently chosen if the cost is 2 or 5 USD and will rarely be chosen if the cost is 10 
Table 6 Optimal 5-year (Y1 through Y5) sequences of interventions for the baseline efficacy scenario when the maximum coverage available for each intervention is $\mathbf{8 0} \%$

\begin{tabular}{|c|c|c|c|c|c|c|c|}
\hline $\begin{array}{l}\text { Geographic } \\
\text { region }\end{array}$ & $\begin{array}{l}\text { Number of } \\
\text { districts }\end{array}$ & $\begin{array}{l}\text { Initial } \\
\text { population state }\end{array}$ & $\begin{array}{l}\text { Y1 intervention } \\
\text { (end pop. state) }\end{array}$ & $\begin{array}{l}\text { Y2 intervention } \\
\text { (end pop. state) }\end{array}$ & $\begin{array}{l}\text { Y3 intervention } \\
\text { (end pop. state) }\end{array}$ & $\begin{array}{l}\text { Y4 intervention } \\
\text { (end pop. state) }\end{array}$ & $\begin{array}{l}\text { Y5 intervention } \\
\text { (end pop. state) }\end{array}$ \\
\hline \multirow[t]{2}{*}{$(D, L)$} & 500 & $(60,15,25)$ & АCТ $80 \%$ & АCТ $60 \%$ & None & ACT $40 \%$ & АСТ $40 \%$ \\
\hline & & & $(90,0,10)$ & $(95,0,5)$ & $(100,0,0)$ & $(100,0,0)$ & $(100,0,0)$ \\
\hline \multirow[t]{2}{*}{$(\mathrm{D}, \mathrm{M})$} & 500 & $(60,15,25)$ & АCТ $80 \%$ & ACT $80 \%$ & АСТ $80 \%$ & ACT $40 \%$ & АCТ $60 \%$ \\
\hline & & & $(90,0,10)$ & $(95,0,5)$ & $(100,0,0)$ & $(100,0,0)$ & $(100,0,0)$ \\
\hline \multirow[t]{2}{*}{$(D, H)$} & 500 & $(60,15,25)$ & АСТ $80 \%$ & None & АСТ $80 \%$ & АCТ $40 \%$ & None \\
\hline & & & $(90,0,10)$ & $(95,0,5)$ & $(100,0,0)$ & $(100,0,0)$ & $(100,0,0)$ \\
\hline \multirow[t]{2}{*}{$(M, L)$} & 500 & $(15,15,70)$ & ACT $80 \%$ & None & АCT $80 \%$ & АCТ $80 \%$ & None \\
\hline & & & $(75,0,25)$ & $(95,0,5)$ & $(100,0,0)$ & $(100,0,0)$ & $(100,0,0)$ \\
\hline \multirow[t]{2}{*}{$(M, M)$} & 500 & $(15,15,70)$ & ACT $80 \%$ & ACT $40 \%$ & АСТ $60 \%$ & АCТ $80 \%$ & ACT $40 \%$ \\
\hline & & & $(75,0,25)$ & $(95,0,5)$ & $(100,0,0)$ & $(100,0,0)$ & $(100,0,0)$ \\
\hline \multirow[t]{2}{*}{$(\mathrm{M}, \mathrm{H})$} & 404 & $(15,15,70)$ & IPT $40 \%$ & LLIN_ACT $80 \%$ & ACT $40 \%$ & АCТ $80 \%$ & None \\
\hline & & & $(20,15,65)$ & $(80,0,20)$ & $(95,0,5)$ & $(100,0,0)$ & $(100,0,0)$ \\
\hline \multirow[t]{2}{*}{$(\mathrm{M}, \mathrm{H})$} & 92 & $(15,15,70)$ & АCT $80 \%$ & АСТ $60 \%$ & АCТ $40 \%$ & None & None \\
\hline & & & $(75,0,25)$ & $(95,0,5)$ & $(100,0,0)$ & $(100,0,0)$ & $(100,0,0)$ \\
\hline \multirow[t]{2}{*}{$(\mathrm{M}, \mathrm{H})$} & 3 & $(15,15,70)$ & None & LLIN_ACT $80 \%$ & ACT $40 \%$ & АСТ $80 \%$ & None \\
\hline & & & $(15,20,65)$ & $(80,0,20)$ & $(95,0,5)$ & $(100,0,0)$ & $(100,0,0)$ \\
\hline \multirow[t]{2}{*}{$(\mathrm{W}, \mathrm{L})$} & 500 & $(10,15,75)$ & LLIN_ACT $80 \%$ & None & АСТ $40 \%$ & АCТ $80 \%$ & ACT $80 \%$ \\
\hline & & & $(75,0,25)$ & $(95,0,5)$ & $(100,0,0)$ & $(100,0,0)$ & $(100,0,0)$ \\
\hline \multirow[t]{2}{*}{$(\mathrm{W}, \mathrm{M})$} & 500 & $(10,15,75)$ & None & ACT_IRS $80 \%$ & None & АCТ $60 \%$ & ACT $60 \%$ \\
\hline & & & $(10,15,75)$ & $(80,0,20)$ & $(95,0,5)$ & $(100,0,0)$ & $(100,0,0)$ \\
\hline \multirow[t]{2}{*}{$(\mathrm{W}, \mathrm{H})$} & 354 & $(10,15,75)$ & None & ACT_IRS $80 \%$ & ACT $40 \%$ & ACT $40 \%$ & None \\
\hline & & & $(10,15,75)$ & $(80,0,20)$ & $(95,0,5)$ & $(100,0,0)$ & $(100,0,0)$ \\
\hline \multirow[t]{2}{*}{$(W, H)$} & 146 & $(10,15,75)$ & None & LLIN_ACT $80 \%$ & None & ACT $40 \%$ & None \\
\hline & & & $(10,15,75)$ & $(75,0,25)$ & $(95,0,5)$ & $(100,0,0)$ & $(100,0,0)$ \\
\hline
\end{tabular}

Geographic region refers to the climate region and distribution cost pair, where the climate region is dry (D), moderate (M) or wet (W), and the distribution cost is low $(\mathrm{L})$, medium $(\mathrm{M})$ or high $(\mathrm{H})$. Number of districts refers to the number of districts that were assigned a given trajectory. Initial population state is the starting $(S, I, R)$ percentages of the region; the end population state for a given year is the resulting $(S, I, R)$ state after distributing the corresponding intervention. The total persondays of malaria infection in this scenario is 1.139 billion, and in all geographic regions, malaria is eradicated over the 5 -year time horizon

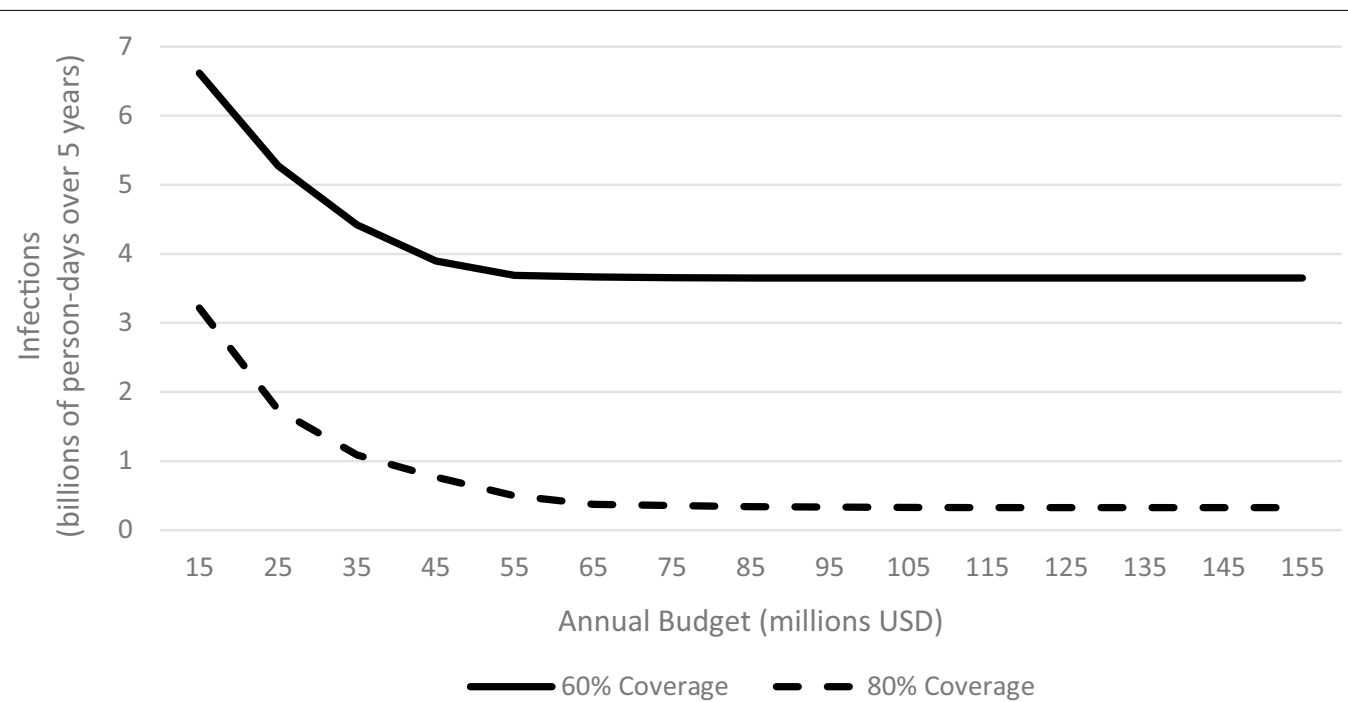

Fig. 4 Total person-days of malaria infection over 5-year horizon as a function of annual budget in the baseline efficacy scenario. The solid line corresponds to a maximum attainable coverages of $60 \%$. The dashed line corresponds to a maximum attainable coverage of $80 \%$ 


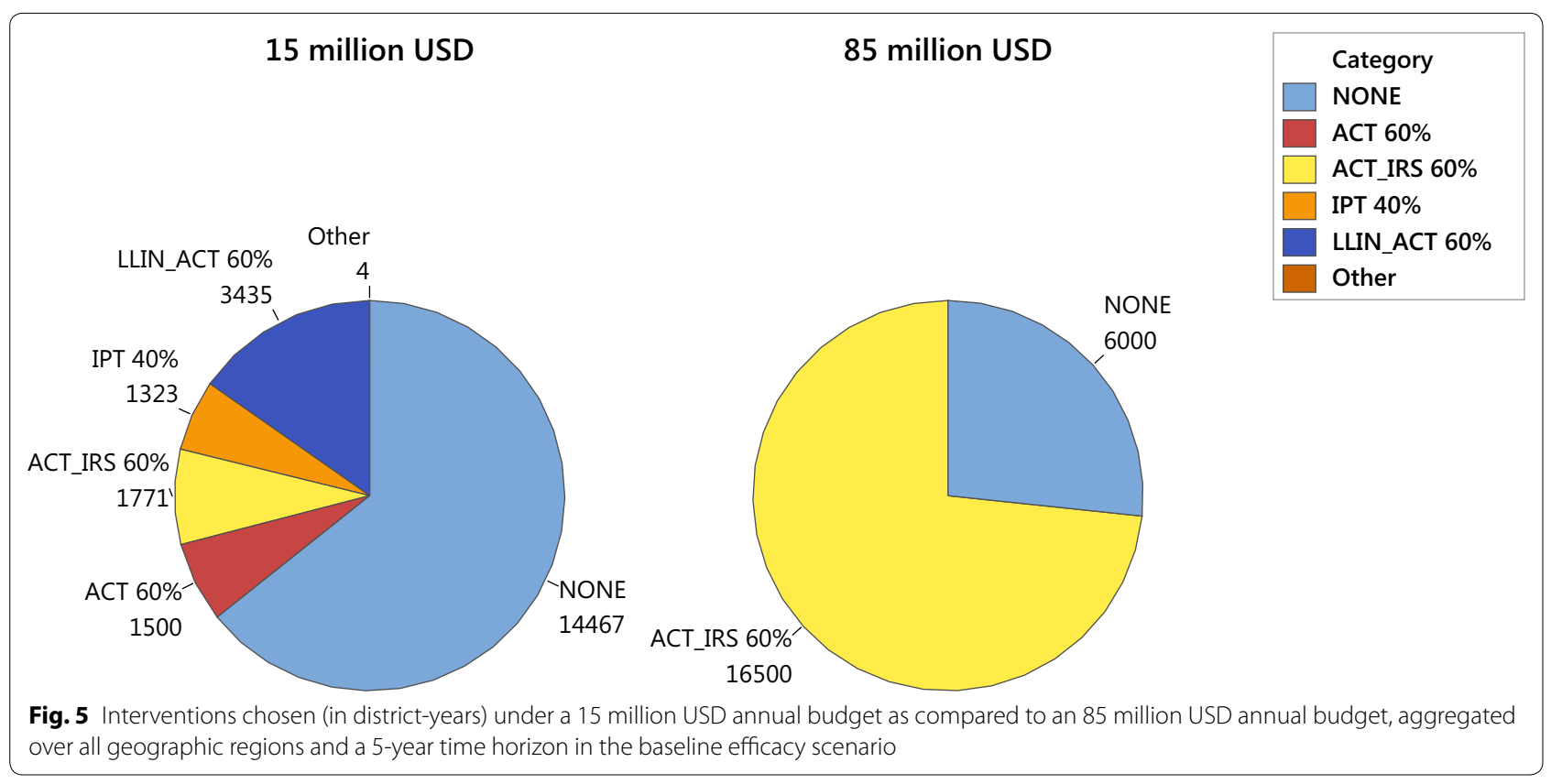

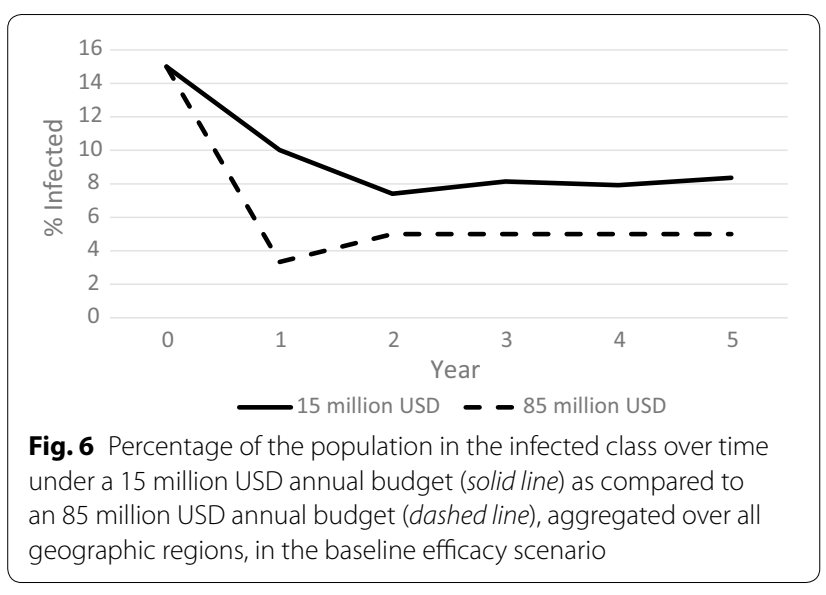

or 20.66 USD. Therefore, it can be concluded that cost is a driving factor in the choice to select vaccines over other interventions. Figure 7 shows the number of districts receiving vaccine, either alone or in combination with IPT, over the 5-year time horizon as a function of vaccine cost, for the baseline efficacy scenario and using $b_{t}=0.005$, and $\gamma_{t}=\frac{1}{5.5}$. When the vaccine cost is 2 USD per person, it is selected quite often, but is selected far less frequently when the cost is 5 USD. Moreover, it is almost never selected at a cost of 10 or 20.66 USD. Shown in the same figure is the person-days of malaria infection in those same instances. Reducing the vaccine cost from 20.66 USD per person to 2 USD per person yields only a $1.5 \%$ reduction in person-days of malaria infection, from 4.51 billion to 4.44 billion.

\section{Role of time horizon}

An important motivation underlying this work is the idea that distributing an intervention changes the malaria transmission dynamics, which could affect future intervention choices. Figure 8 compares the interventions chosen in the first year of the 5-year time horizon to those chosen if the time horizon is only a single year. As mentioned above, in the first year of the 5-year time horizon, resources are focused primarily on the dry and moderate climate regions that receive either ACT alone at $60 \%$ coverage, or ACT in combination with LLIN at $60 \%$ coverage. Most of the medium-to-high distribution cost districts in the wet regions receive no treatment during year 1 . Nearly 400 of the low distribution cost districts in the wet regions get $20 \%$ coverage of LLIN with ACT, and the remaining 100 get $60 \%$ coverage of LLIN with ACT. By contrast, if only a 1-year time horizon is used, the solution changes. Dry regions (at all distribution costs) again receive ACT alone at $60 \%$ coverage. Moderate climate regions having low or medium distribution costs receive LLIN in combination with $\mathrm{ACT}$ at $60 \%$ coverage, as do 324 moderate climate regions having high distribution costs. However, now 175 moderate climate districts having high distribution costs drop down to no intervention, and in return, all 500 wet climate districts having low distribution costs receive LLIN with ACT at $60 \%$ coverage, which is substantially higher than before. Thus, incorporating a multi-year planning horizon that anticipates changes in the malaria transmission as a result of the interventions distributed does indeed affect the optimal choice of intervention. 


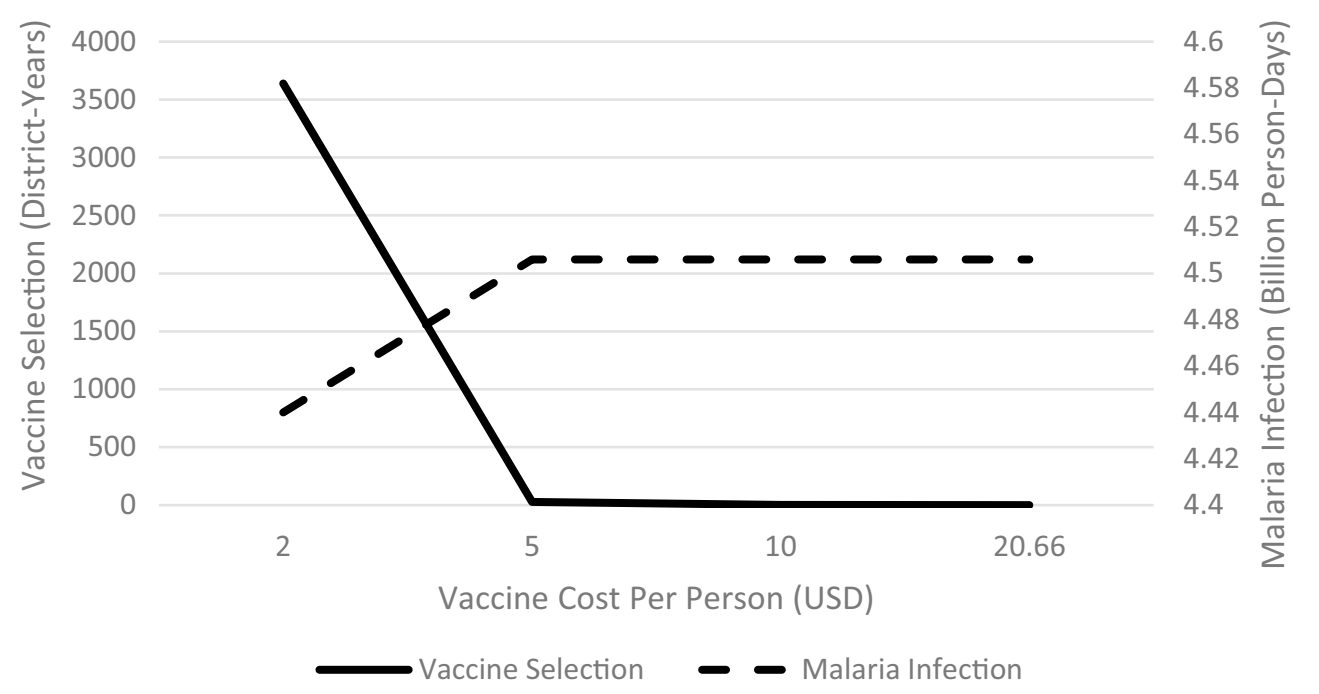

Fig. 7 Vaccine selection (in number of district-years) and person-days of malaria infection versus vaccine cost, over 5-year time horizon, in the baseline efficacy scenario

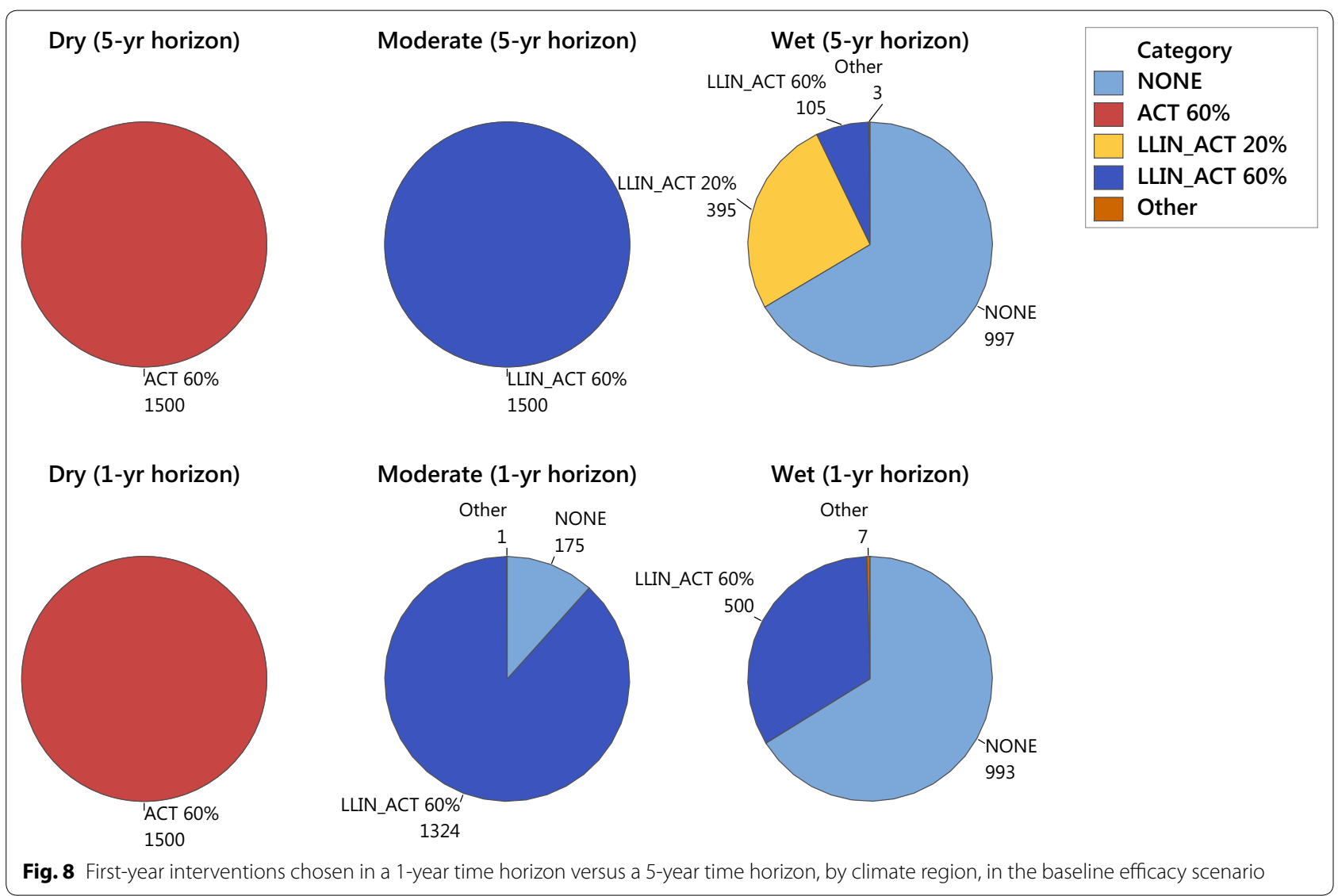

\section{Role of climate}

There is a noticeable qualitative difference in the types of treatments distributed to the three climate regions considered. Aggregating over all years and distribution cost categories for the baseline efficacy scenario, the first row of Fig. 9 shows the number of districts receiving 


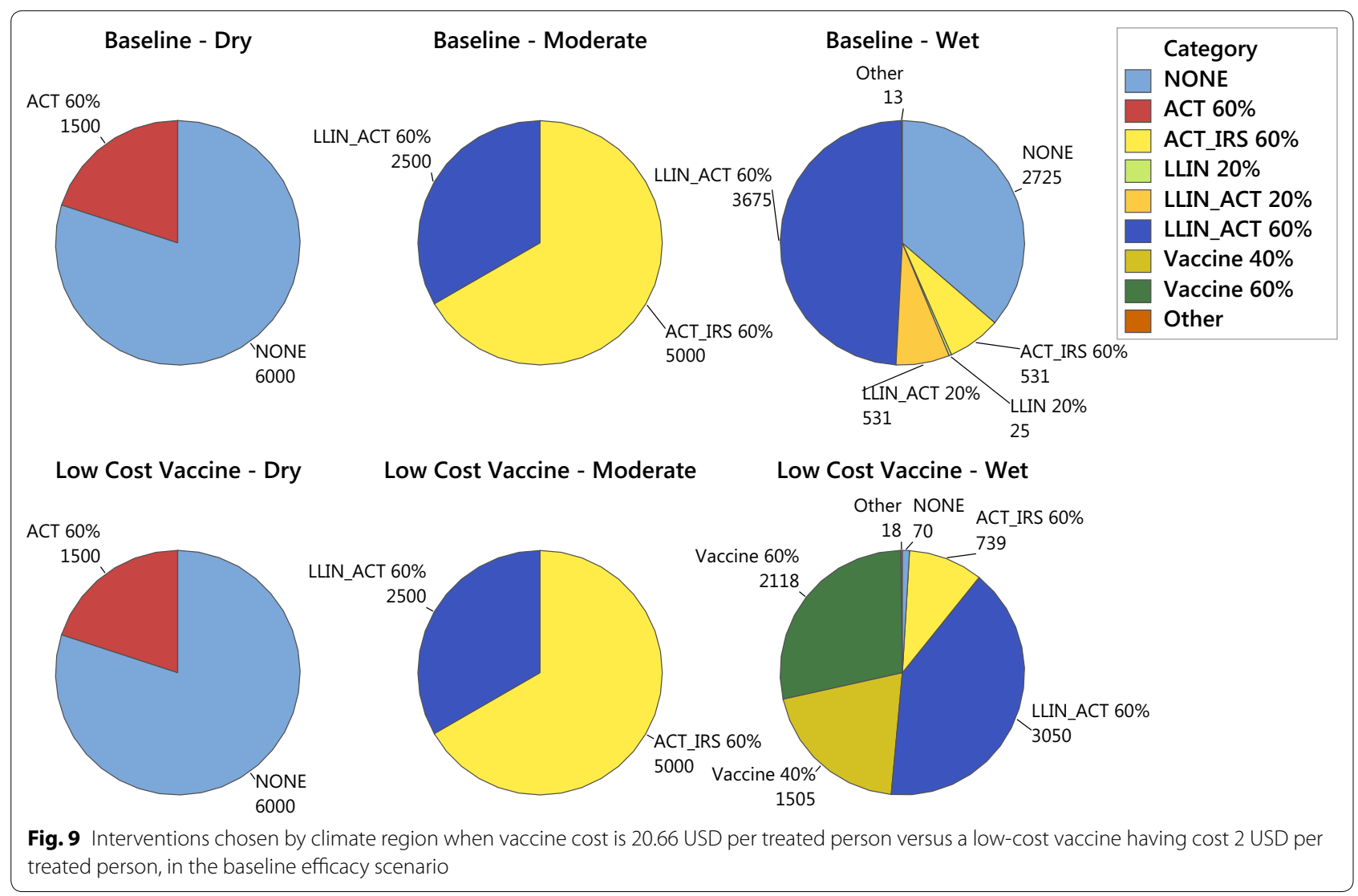

each type of treatment, separated by climate region. Dry regions are adequately served by $\mathrm{ACT}$ alone; moderate regions require $\mathrm{ACT}$ in combination with either LLIN or IRS; and wet regions get LLIN alone, LLIN with ACT, ACT with IRS, and a handful of others (though as discussed earlier, this variety is likely the result of the model using the available budget because no treatment at $60 \%$ coverage is very successful at reducing malaria in the wet regions).

If a lower-cost vaccine is available at 2 USD per person per year, the second row of Fig. 9 shows that dry regions again receive exclusively no intervention and ACT, and moderate regions again receive exclusively ACT in combination with either IRS or LLIN. Now, however, in the wet regions, the number of years of "no intervention" drops significantly, from 2725 to 70 , and vaccine use, at either 40 or $60 \%$ coverage, comprises nearly $50 \%$ of the pie chart.

The takeaway messages are that a single choice of intervention across all climate types is unlikely to be optimal, and that the development of a low-cost malaria vaccine is likely to be of greatest use in regions with high mosquito densities; drier areas are better served by ACT, alone or in combination with IRS and LLIN.

\section{Conclusions}

Because the model is very sensitive to the disease transmission parameter values used, it is best suited for qualitative interpretations about relative benefits of certain interventions. For instance, while common sense might suggest that intervention resources should be focused on wet climate regions with high mosquito counts, the results of the simulations with a maximum coverage of $60 \%$ suggest the opposite: to reduce person-days of malaria infection, it might be better to invest resources on areas where interventions can dramatically reduce the prevalence of malaria, rather than expend resources on areas where malaria is likely to persist, despite best efforts. But if coverage closer to $80 \%$ is attainable, then malaria can be combatted in wet climate regions. Likewise, the model can illustrate the sensitivity of the optimal policy to certain parameters. For example, the optimal sequence of interventions varies by climate type (as represented by mosquito density), suggesting that a onesize-fits-all approach to malaria eradication is not optimal. The sensitivity of the model to parameter assumptions also signals that prior to using the model to guide policy in any given region, the choice of parameter values would first need to be calibrated to match known malaria prevalence rates in the region. 
Future refinements of the model could address acquired resistance to interventions, age-dependent immunity, spatial effects of human or mosquito migration, and computational tractability. Drug resistance in malaria parasites and insecticide resistance in mosquitoes are major challenges to control and eradication efforts [41-43]. Implementing resistance in this model would require tracking decreased effectiveness of treatment after use in multiple consecutive years. This would increase the computational challenge of solving the model, however, as the costs and benefits of choosing a particular intervention in a given year would depend not only on the $(S, I, R)$ population state but also on the sequence of interventions chosen in prior years. Likewise, incorporating age-dependent immunity or spatial effects would also require an increase in the number of population compartments in the $(S, I, R)$ model. Already, computational power was limited, even using a $5 \%$ population resolution. The bottleneck appears to be in the formulation of the ILP using AMPL. Although the data file is only $2 \mathrm{MB}$ at $5 \%$ resolution and $11 \mathrm{MB}$ at $2 \%$ resolution, loading the $5 \%$ resolution data file into AMPL took approximately $15 \mathrm{~min}$ on a 32 -core, 128 GB RAM parallel compute server located in the Harvey Mudd College Mathematics Department, and attempting to load the data file for the $2 \%$ resolution case exceeded the available $128 \mathrm{~GB}$ of RAM on the server. Once loaded, the $5 \%$ resolution model was subsequently solved by the CPLEX solver within seconds. The technical staff at the NEOS server (an online server for optimization solvers on which earlier tests were run [44-46]) who are familiar with these modelling languages suggested using a more efficient modelling language than AMPL for formulating the optimization model; this is left as future work.

Given the growing interest in malaria eradication, the WHO Global Malaria Programme cites the need for operations research studies to determine the best intervention strategies in areas where transmission dynamics are changing as malaria is being eliminated. They also present a list of priority research questions that includes questions about safety, access, and community involvement [2]. This paper presents a flexible modelling framework that can guide such decisions. The model permits a multi-year planning horizon over areas characterized by disparate infrastructure and climate. Given inputs of the per-person cost of each intervention and the effects each intervention has on malaria disease transmission parameters, the model provides a sequence of interventions over a fixed time horizon that minimizes person-days of malaria infection subject to an annual budget. Moreover, this model can be adapted to the treatment of other infectious diseases.

\section{Authors' contributions}

HJD and SEM wrote the paper. HJD, AG, and CJO conducted literature review, gathered data, implemented the computational model, wrote the simulations, and wrote an initial draft of the paper. SEM proposed the concept for the model, guided model development and analysis, finalized the computational model and simulations, analysed the model, and secured funding for the work. All authors read and approved the final manuscript.

\section{Author details}

${ }^{1}$ University of Colorado Boulder, 526 UCB, University of Colorado, Boulder, CO 80309-0526, USA. ${ }^{2}$ Harvey Mudd College, 301 Platt Blvd, Claremont, CA 91711, USA.

\section{Acknowledgements}

This project was supported by grants to Harvey Mudd College for student and faculty research from the Arnold and Mabel Beckman Foundation, the Howard Hughes Medical Institute, the Fletcher Jones Foundation, the Andrew W. Mellon Foundation, and The Rose Hills Foundation. Additionally, the authors thank Shanika Lazo for her contributions to this work, and Katarina Hoeger, Tracey Luke, Taryn Ohashi, Tristan Williams and Flora Xu for their contributions to an earlier version of the model presented here. The authors also thank two anonymous reviewers for their suggestions which greatly improved this work.

\section{Competing interests}

The authors declare that they have no competing interests.

Received: 8 September 2015 Accepted: 18 February 2016

Published online: 01 March 2016

\section{References}

1. World Health Organization. Malaria fact sheet. Accessed 01 Mar 2014. Available from: http://www.who.int/mediacentre/factsheets/fs094/en/.

2. World Health Organization. Global Malaria Programme. Meeting report: Planning meeting for operational research on malaria elimination. 2013.

3. Centers for disease control and prevention. Insecticide-treated bed nets. Accessed 01 Mar 2014. Available from: http://www.cdc.gov/malaria/ malaria worldwide/reduction/itn.html.

4. World Health Organization. Guidelines for laboratory and field testing of long-lasting insecticidal mosquito nets. 2013.

5. Pluess B, Tanser FC, Lengeler C, Sharpe BL. Indoor residual spraying for preventing malaria. Cochrane Database Syst Rev. 2010. Available from: http://onlinelibrary.wiley.com/doi/10.1002/14651858.CD006657.pub2/ abstract.

6. Aponte JJ, Schellenberg D, Egan A, Breckenridge A, Carneiro I, Critchley J, et al. Efficacy and safety of intermittent preventive treatment with sulfadoxine-pyrimethamine for malaria in African infants: A pooled analysis of six randomized, placebo-controlled trials. Lancet. 2009:374(9700):1533-42.

7. Doolan DL, Dobaño C, Baird JK. Acquired immunity to malaria. Clin Microbiol Rev. 2009;22(1):13-36.

8. Malaria Consortium. Artemisinin-based combination therapy. Accessed 01 Aug 2014. Available from: http://www.malariaconsortium.org/page. php?id=112.

9. Duffy PE, Mutabingwa TK. Artemisinin combination therapies. Lancet. 2006;367(9528):2037-9.

10. Crompton PD, Pierce SK, Miller LH. Advances and challenges in malaria vaccine development. J Clin Invest. 2010;120(12):4168-78.

11. Dimitrov NB, Moffett A, Morton DP, Sarkar S. Selecting malaria interventions: a top-down approach. Comput Oper Res. 2013;40(9):2229-40.

12. Ross R. Some a priori pathometric equations. Br Med J. 1915;1(2830):5467. Available from: http://www.ncbi.nlm.nih.gov/pmc/articles/ PMC2302055/pdf/brmedj07224-0010.pdf.

13. Mandal S, Sarkar RR, Sinha S. Mathematical models of malaria-a review. Malar J. 2011;10:202. Available from: http://www.malariajournal.com/ content/10/1/202.

14. Lindblade KA, Dotson E, Hawley WA, Bayoh N, Williamson J, Mount D, et al. Evaluation of long-lasting insecticidal nets after 2 years of household use. Trop Med Int Health. 2005;10(11):1141-50. 
15. Killeen GF, Kihonda J, Lyimo E, Oketch FR, Kotas ME, Mathenge E, et al. Quantifying behavioural interactions between humans and mosquitoes: Evaluating the protective efficacy of insecticidal nets against malaria transmission in rural Tanzania. BMC Infect Dis. 2006:6:161.

16. Bousema T, Okell L, Shekalaghe S, Griifin JT, Omar S, Sawa P, et al. Research revisiting the circulation time of Plasmodium falciparum gametocytes: molecular detection methods to estimate the duration of gametocyte carriage and the effect of gametocytocidal drugs. Malar J. 2010;9:136. Available from: http://www.malariajournal.com/content/9/1/136.

17. Garner P, Graves PM. The Benefits of artemisinin combination therapy for malaria extend beyond the individual patient. PLoS Med. 2005;2(4):e105. doi:10.1371/journal.pmed.0020105.

18. Chandramohan D, Owuso-Ageyi S, Carneiro I, Awine T, Amponsa-Achiano $\mathrm{K}$, Mensah N, et al. Cluster randomised trial of intermittent preventive treatment for malaria in infants in area of high, seasonal transmission in Ghana. Br Med J. 2005;331(727):727-33.

19. Grobusch MP, Lell B, Schwarz NG, Gabor J, Dörnemann J, Pötschke M, et al. Intermittent preventive treatment against malaria in infants in Gabon: a randomized, double-blind, placebo-controlled trial. J Infect Dis. 2007;196(1):1595-602

20. Prosper O, Ruktanonchai N, Martcheva M. Optimal vaccination and bed net maintenance for the control of malaria in a region with naturally acquired immunity. J Theor Biol. 2014;353:142-56.

21. Bojang KA, Milligan PJ, Pinder M, Vigneron L, Alloueche A, Kester KE, et al. Efficacy of RTS, S/ASO2 malaria vaccine against Plasmodium falciparum infection in semi-immune adult men in The Gambia: A randomized trial. Lancet. 2001;358(9297):1927-34.

22. Asante KP, Abdulla S, Agnandji S, Lyimo J, Vekemans J, Soulanoudjingar S, et al. Safety and efficacy of the RTS, S/AS01E candidate malaria vaccine given with expanded programme on immunisation vaccines: 19 month follow-up of a randomised, open-label, phase 2 trial. Lancet Infect Dis. 2011;11(10):741-9.

23. Koella JC, Antia R. Epidemiological models for the spread of anti-malaria resistance. Malar J. 2003;2:3. Available from: http://www.malariajournal. com/content/2/1/3.

24. Dawes EJ, Churcher TS, Zhuang A, Sinden RE, Basanez M. Anopheles mortality is both age and Plasmodium density dependent: Implications for malaria transmission. Malaria J. 2009;8:228. Available from: http://www. malariajournal.com/content/8/1/228.

25. Koudou BG, Malone D, Hemingway J. The use of motion detectors to estimate net usage by householders, in relation to mosquito density in central Côte d'Ivoire: preliminary results. Parasit Vectors. 2014;7:96.

26. Smith DL, McKenzie FE. Statics and dynamics of malaria infection in Anopheles mosquitoes. Malar J. 2004;3:13. Available from: http://www. malariajournal.com/content/3/1/13.

27. Aron JL, May RM. The population dynamics of malaria. In: Anderson RM, editor. The population dynamics of infectious diseases: theory and applications. London: Chapman and Hall; 1982. p. 168-9.

28. Sutherland CJ, Ord R, Dunyo S, Jawara M, Drakeley CJ, Alexander N, et al. Reduction of malaria transmission to Anopheles mosquitoes with a six-dose regimen of co-artemether. PLoS Med. 2005;2(4):e92. doi:10.1371/ journal.pmed.0020092.

29. White MT, Conteh L, Cibulskis R, Ghani AC. Costs and cost-effectiveness of malaria control interventions - a systematic review. Malar J. 2011;10:337. Available from: http://www.malariajournal.com/content/10/1/337.
30. World Health Organization. Estimating population access to ITNs versus quantifying for procurement for mass campaigns. 2014. Available from: http://www.who.int/malaria/publications/atoz/who-clarification-estimating-population-access-itn-mar2014.pdf.

31. Seo MK, Baker P, Ngoc-Lan K. Cost-effectiveness analysis of vaccinating children in Malawi with RTS,S vaccines in comparison with long-lasting insecticide-treated nets. Malar J. 2014;13:66. Available from: http://www. malariajournal.com/content/13/1/66.

32. United States Bureau of Labor Statistics. Inflation calculator. Accessed July 2015. Available from: http://www.bls.gov/data/inflation_calculator.htm.

33. Chitnis N, Hyman JM, Cushing JM. Determining important parameters in the spread of malaria through the sensitivity analysis of a mathematical model. Bull Math Biol. 2008;70(5):1272-96.

34. Central Intelligence Agency. The world factbook: Kenya; Accessed June 2014. Available from: https://www.cia.gov/library/publications/ the-world-factbook/geos/ke.html.

35. Filipe JAN, Riley EM, Drakeley CJ, Sutherland CJ, Ghani AC. Determination of the processes driving the acquisition of immunity to malaria using a mathematical transmission model. PLoS Comput Biol. 2007;3(12):2569-79.

36. Anderson RM, May RM. Infectious diseases of humans: dynamics and control. Oxford: Oxford University Press; 1991.

37. Kakkilaya BS. Malaria site: immunity; Accessed July 2015. Available from: http://www.malariasite.com/immunity/.

38. Zhou G, Githeko AK, Minakawa N, Yan G. Community-wide benefits of targeted indoor residual spray for malaria control in the Western Kenya Highland. Malaria J. 2010;9:67. Available from: http://www.malariajournal. com/content/9/1/67.

39. Olotu A, Fegan G, Wambua J, Nyangweso G, Awuondo KO, Leach A, et al. Four-year efficacy of RTS, S/AS01E and its interaction with malaria exposure. N Engl J Med. 2013;368(12):1111-20.

40. President's Malaria Initiative. FY 2013 Kenya-Revised funding table. 2013. Available from: http://www.pmi.gov/where-we-work/kenya.

41. World Health Organization. Antimalarial drug resistance. Available from: http://www.who.int/malaria/areas/drug_resistance/overview/en/.

42. Kim Y, Schneider KA. Evolution of drug resistance in malaria parasite populations. Nature education knowledge. 2013;4(8):6. Available from: http://www.nature.com/scitable/knowledge/library/ evolution-of-drug-resistance-in-malaria-parasite-96645809.

43. Edi VA, Koudou BG, Jones CM, Weetman D, Ranson H. Multiple-insecticide resistance in Anopheles gambiae mosquitoes, southern Côte d'Ivoire. Emerg Infect Dis. 2012;18(9):1508-11. doi:10.3201/eid1809.120262.

44. Czyzyk J, Mesnier MP, Moré JJ. The NEOS server. IEEE Comput Sci Eng. 1998;5(3):68-75.

45. Dolan E. The NEOS server 4.0 administrative guide. Technical memorandum ANL/MCS-TM-250. Mathematics and computer science division, Argonne national laboratory. 2001. Available from: http://info.mcs.anl. gov/pub/tech_reports/reports/TM-250.pdf.

46. Gropp W, Moré JJ. Optimization environments and the NEOS server. In: Buhmann MD, Iserles A, editors. Approximation theory and optimization. Cambridge: Cambridge University Press; 1997. p. 167-82.

\section{Submit your next manuscript to BioMed Central and we will help you at every step:}

- We accept pre-submission inquiries

- Our selector tool helps you to find the most relevant journal

- We provide round the clock customer support

- Convenient online submission

- Thorough peer review

- Inclusion in PubMed and all major indexing services

- Maximum visibility for your research

Submit your manuscript at www.biomedcentral.com/submit

() Biomed Central 